Pontifícia Universidade católica do Rio de Janeiro

\title{
Atribuição de Marketing: obstáculos e desafios na mensuração de resultado no marketing digital
}

\section{Felipe Lemos Pupe}

Trabalho de Conclusão de Curso

Centro de clênCIAs sociais - CCS

Departamento de Administração

Graduação em Administração de Empresas 
Felipe Lemos Pupe

\section{Atribuição de Marketing: obstáculos e desafios na mensuração de resultado no marketing digital}

Trabalho de Conclusão de Curso

Trabalho de Conclusão de Curso, apresentado ao programa de graduação em Administração da PUC-Rio como requisito parcial para a obtenção do título de graduação em Administração.

Orientador(a) : Vivian Peuker Sardon Steinhauser

Rio de Janeiro

10 de novembro de 2021. 
"Sei que metade de minha propaganda é inútil, mas não sei qual metade"

John Wanamaker, criador do conceito de lojas de departamentos e publicitário 


\section{Agradecimentos}

À minha família que fez todos os sacrifícios e esforços para que eu chegasse até aqui. Ao meu pai, à minha mãe, à minha avó e ao meu irmão que vivenciaram momentos importantes da minha trajetória até aqui.

Aos meus amigos que foram fundamentais para compartilhar minhas, frustrações, desafios, incertezas e alegrias ao longo de toda graduação.

Para esse trabalho em especial, algumas pessoas tiveram suma importância e não poderia aqui deixar de agradecer individualmente. Às minhas professoras Vivian e Liana que apoiaram e orientaram com muita paciência e competência. Aos participantes das entrevistas, gestores e coordenadores em atividade na área de marketing digital que cederam seus tempos preciosos para contribuir para a minha pesquisa. Marina, Marcelo, Camila, Gian e Gustavo, muito obrigado! À minha mãe, que empregou todo o seu conhecimento adquirido na faculdade de Letras para corrigir a ortografia e sugerir ajustes para melhorar a fluidez do texto.

Agradeço a todos de coração. Sem vocês essa graduação e esse trabalho não teriam acontecido. 


\section{Resumo}

Lemos Pupe, Felipe. Atribuição de Marketing: obstáculos e desafios na mensuração de resultado em marketing digital. Rio de Janeiro, 2021. p. 49

- Trabalho de Conclusão de Curso - Departamento de Administração. Pontifícia Universidade Católica do Rio de Janeiro.

A era da internet inaugurou uma jornada de compra cada vez mais complexa e com múltiplos pontos de contato. Esses diversos pontos de contato influenciam o consumidor a tomar ou não a decisão de compra. As empresas, nesse novo contexto, ganharam o desafio de desenvolver um modelo capaz de medir com precisão o impacto das ações de marketing para o crescimento da receita da empresa. Apesar do volume de dados sobre as interações do usuário com as comunicações de marketing, implementar um modelo de atribuição personalizado para a realidade de um negócio está longe hoje de ser algo trivial. O objetivo deste trabalho é identificar os principais obstáculos que impedem profissionais de marketing no Brasil de implementar um modelo de atribuição mais eficaz para uma jornada de múltiplos pontos de contato.

Palavras- chave

atribuição de conversão, atribuição multi-canal, atribuição de marketing

\section{Abstract}

Lemos Pupe, Felipe. Marketing Attribution: barriers and challenges on measurement of return on digital marketing investment. Rio de Janeiro, 2021. p. 49. Trabalho de Conclusão de Curso - Departamento de Administração. Pontifícia Universidade Católica do Rio de Janeiro.

The internet era had ushered in a complex shopping journey with multiple touchpoints, which influence consumer behavior in favor or against the buying decision. Companies, in this new context, had received the challenge of developing a model capable of accurately measuring the impact of marketing efforts on the company's revenue growth. Despite the high volume of data on user interactions with marketing communications, implementing an attribution model tailored to the reality of a business is far from trivial today. The objective of this paper is to identify the main obstacles that prevent marketers in Brazil from implementing a more effective attribution model for a journey with multiple touchpoints.

Key-words

conversion attribution, multi-channel attribution, marketing attribution 


\section{Sumário}

1 O tema e o problema de estudo 1

1.1. Introdução ao tema e ao problema do estudo 1

1.2. Justificativa e relevância do estudo 3

1.3. Objetivos do estudo 4

1.4. Delimitação e foco do estudo 5

2 Revisão de literatura 4

2.1. Atribuição de conversão

2.2. Conceitos fundamentais

2.2.1.Comunicação e canais de marketing 6

2.2.2. Canais iniciados pela empresa e pelo cliente 7

2.2.3. Efeitos de "Carryover" e "Spillover" 7

2.3. Tipos de Abordagens 8

3 Métodos e procedimentos de coleta e de análise de dados do estudo

3.1. Etapas de coleta de dados 14

3.2. Fontes de informação selecionadas para coleta de dados 15

3.3. Procedimentos e instrumentos de coleta de dados utilizados no estudo 15

3.4. Formas de tratamento e análise dos dados coletados para o estudo16

3.5. Limitações do Estudo

4 Apresentação e análise dos resultados 17

4.1. Perfil dos entrevistados 19

4.2. Situação atual de modelo de atribuição 19

4.2.1. Métodos e plataformas para medir conversão 19

4.2.2. Formas de medir o retorno sobre o investimento em marketing 20 
4.2.3. Modelo de atribuição utilizado

4.3. Tipos de análises feitas para fazer o planejamento de investimento e mix de mídias

4.4. Principais dificuldades e desafios

4.5. Análise comparativa das respostas observadas

27

5 Conclusões e recomendações para novos estudos

6. Referências Bibliográficas

Apêndice 1

Apêndice 2

\section{Lista de Figuras}

Figura 1: Ferramenta de Comparação de Modelos

\section{Lista de Tabelas}




\section{Introdução}

\subsection{Introdução ao tema e ao problema do estudo}

A internet possibilitou ao consumidor um acesso quase que ilimitado a informações sobre os produtos pelos quais se interessa. Constantes inovações na publicidade digital permitem aos anunciantes alcançar consumidores por meio de uma variedade de formatos e canais digitais (ABHISHEK et al., 2012). Um típico consumidor é impactado por diversos tipos de anúncios online de uma empresa, desde anúncios de display que aparecem nos espaços publicitários dos sites a links patrocinados em motores de busca e anúncios em vídeos em redes como o YouTube. Essas inúmeras interações com uma campanha publicitária de uma empresa caracterizam uma jornada "multi-touch". (KAUSHIK, 2012). As mesmas influenciam o comportamento do consumidor de uma maneira complexa, já que o impacto de um anúncio para fazer o consumidor avançar no seu processo de decisão de compra vai depender tanto do seu estado de engajamento com a empresa, quanto do histórico de anúncios aos quais ele foi exposto anteriormente (ABHISHEK et al., 2012). Nesse contexto, identificar quais são os formatos ou canais mais eficientes para determinado objetivo de campanha de marketing se tornou um dos grandes desafios dos profissionais de marketing digital. Os anunciantes possuem o desafio de quantificar a contribuição que cada anúncio tem para a decisão final de compra do consumidor. Ele é comumente conhecido como o problema da atribuição, o qual busca calcular como o crédito para uma ação de conversão deve ser dividido entre os diversos anúncios que atingiram o consumidor até o momento da compra (ABHISHEK et al., 2017).

O problema da atribuição não é um desafio novo no marketing. Desenvolver um modelo para medir com precisão o impacto de ações de marketing para o crescimento da receita da empresa já era necessário nos canais de mídia tradicionais como TV e imprensa. (ABHISHEK et al., 2017, Rocha, 2019). Entretanto, os canais digitais permitem tratar com maior precisão o problema da atribuição uma vez que os profissionais podem acessar dados desagregados e a nível individual das reações dos consumidores aos anúncios, 
o que não era possível com as mídias offline (ABHISHEK, 2017). Apesar de todo desenvolvimento das ferramentas de mensuração de resultados de anúncios online, muitas empresas ainda utilizam modelos simplistas para fazer a atribuição (PWC, 2014; ABHISHEK et. al, 2016; eMarketer, 2018), como o último clique (last-touch attribution, LTA) e o primeiro clique (first-touch attribution, FTA). $70 \%$ dos anunciantes ainda usam modelo last-click ou first-click", de acordo com uma pesquisa, feita em 2018 pela eMarketer, com 2274 profissionais de marketing de performance no Reino Unido e nos EUA.

Esses modelos são menos precisos, pois atribuem todo o crédito da conversão a um único clique ou impressão que aconteceu logo antes da conversão (LTA) ou no contato com o anúncio que fez o usuário interagir com o site da empresa pela primeira vez (ABHISHEK et al., 2012). Os modelos de atribuição que consideram a contribuição de um único ponto de contato para gerar uma conversão são conhecidos como modelos "single-touch". (ZAREMBA, 2020; JAVAWARDANE et al. 2015; Ji et al. 2015; SHULTZ \& DELLNITZ, 2018).

O usuário pode ter sido influenciado por um banner de display, depois um anúncio em vídeo que contava mais detalhes sobre o produto e depois uma publicação patrocinada na rede social com uma oferta por tempo limitado, por exemplo. Depois de ser impactado pelas comunicações de mídia paga nas fases de consciência e consideração, o consumidor, agora já está muito mais engajado em relação ao produto da empresa e, com isso, decide fazer a compra fazendo uma pesquisa num site de busca, como Google Search, onde ele clica no anúncio de pesquisa da empresa. A partir do modelo de último clique, todo o crédito da conversão seria atribuído a esse último ponto de contato, sugerindo que todas as comunicações anteriores não produziram nenhum impacto nessa decisão do consumidor. Esse modelo acabaria induzindo o profissional de marketing a uma superestimação da eficiência do anúncio de pesquisa de busca em detrimento dos anúncios anteriores que tornaram o usuário mais engajado em relação ao produto ou serviço.

Modelos de atribuição baseados em dados de toda a jornada do usuário são mais justos e permitem aos profissionais e gestores de marketing tomar decisões mais assertivas em relação a orçamento, estratégia e distribuição de recursos de marketing. Essa mensuração precisa é chave para os gestores no momento de distribuir o orçamento de publicidade entre os canais e os formatos mais eficientes. De forma resumida, um modelo de atribuição de conversão 
apropriado busca definir os critérios que irão medir o desempenho dos canais digitais.

\subsection{Justificativa e relevância do estudo}

Nos últimos anos, o tema da atribuição de conversão vem ganhando cada vez mais relevância na pesquisa acadêmica. Uma ampla revisão de literatura mostra que os estudos científicos ainda não adotaram uma metodologia de atribuição de conversão comumente aceita (ZAREMBA, 2020). A pesquisa de Zaremba (2020) indica um número significativo de 11 metodologias diferentes analisadas pela literatura e nenhum resultado se aproxima de apontar a melhor delas. Zaremba também mostra que o número de artigos científicos tratando sobre atribuição de conversão vem crescendo nos últimos 9 anos. Na primeira metade da década, 23 artigos haviam sido produzidos, e na segunda metade, o número já chega a 34, sem considerar os artigos publicados em 2020. No cenário nacional, alguns trabalhos dentro da área do marketing digital e analytics mencionam a importância do tópico, mas encontram-se poucos trabalhos produzidos no Brasil cujo foco principal de estudo seja atribuição de conversão. Percebe-se, portanto, uma lacuna na literatura nacional de estudos que investiguem com mais profundidade o tema dentro do ambiente de marketing digital brasileiro.

Ao mesmo tempo, no contexto gerencial, o tema da atribuição de conversão ganha crescentemente espaço nas discussões de estratégia do chamado marketing de performance, tendo em vista que os gestores que trabalham com mídias pagas enfrentam um desafio constante de alocar o orçamento de mídia online disponível da maneira mais otimizada possível. Entender e avaliar com precisão a eficiência dos canais digitais é fundamental para que gestores de marketing possam tomar decisões mais assertivas em relação a distribuição de orçamento, o qual na mídia digital pode ser mudado em uma frequência diária.

Portanto, o modelo de atribuição de conversão passa a ser visualizado pelos próprios gestores de marketing como uma das questões mais significativas para comprovar o impacto do investimento em marketing no crescimento do 
resultado financeiro da empresa. $54 \%$ dos anunciantes reconhecem a atribuição de conversão como um dos obstáculos mais difíceis de superar na sua gestão estratégica, segundo uma pesquisa com 468 gestores sênior de marketing ao redor do mundo (eMarketer, 2018). Mensuração e otimização da contribuição de marketing para gerar valor para negócio tem se tornado um tópico chave para líderes do nível estratégico das empresas (Forbes \& Marketing Accountability Standards Board, 2018; American Marketing Association, Delloite, \& Fuqua School of Business, 2019).

\subsection{Objetivo do estudo}

O objetivo deste trabalho é identificar os principais obstáculos que impedem profissionais de marketing no Brasil de implementar um modelo de atribuição mais eficaz para uma jornada de múltiplos pontos de contato. A partir de uma revisão de literatura do tópico, esse trabalho se propõe a mapear as características de um modelo apropriado de atribuição de conversão e identificar os principais pré-requisitos necessários para implementá-lo.

O estudo traz a contribuição de aprofundar o tema da atribuição de conversão na literatura nacional e apresentar informações do contexto brasileiro de gestão de mídia paga a respeito da percepção de gestores e profissionais de marketing sobre o tema. Em segundo lugar, o trabalho se propõe a gerar implicações aos gestores e profissionais para mapear os principais desafios vivenciados por empresas que possuem grandes investimentos em mídias pagas e que fazem grande parte das suas conversões de modo online.

\subsection{Delimitação do estudo}

Embora esse estudo possa gerar implicações para todo tipo de empresa que investe em anúncios online, o foco será em investigar a realidade de atribuição de conversão de empresas que possuem grande parte das suas ações de 
conversão de compra no meio online. Modelos que levem em consideração conversão de compra que acontece em lojas físicas irá provavelmente envolver outros desafios de mensuração de resultados. Além disso, a análise de atribuição de conversão muitas vezes pode deixar de fora o impacto de canais que às vezes nem pertencem à empresa, mas contribuem para motivar o usuário chegar na conversão, como sites independentes, comparadores de preços e comunidades de usuários. Este trabalho irá buscar investigar e gerar implicações para a gestão das mídias que a empresa possui total controle, como mídia paga, email marketing, redes sociais, blogs etc. Contudo, como a mídia paga é o tipo de mídia de marketing que gestores têm maior autonomia e flexibilidade para fazer mudanças de orçamento, acredita-se que essa tenha maior prioridade em relação a atribuição de conversão.

Os dados do estudo serão coletados através de questionário qualitativo com gestores, coordenadores e diretores de marketing de empresas com participação nos aspectos táticos e estratégicos de web analytics. A pesquisa qualitativa não tem, portanto, perfil estatístico e, por isso, os resultados não podem ser generalizados. O contexto do nicho das empresas entrevistadas será variado e, com isso, a natureza da jornada de compra do produto pode influenciar na complexidade dos desafios para implementação de um modelo orientado por dados. O estudo se limita a identificar obstáculos das empresas de forma genérica, sem considerar desafios específicos do negócio de cada uma.

\section{Revisão de literatura}

\subsection{Atribuição de Conversão}

A atribuição de conversão é definida como a ciência da utilização de dados analíticos avançados para associar o valor adequado a uma ação realizada pelo cliente em cada ponto de contato de marketing (MOFFET, PILECKI, MCADAMS, 2014). Pontos de contato de marketing é toda interação entre o consumidor e a marca que é experienciada pelo consumidor por meio de um "canal", que é uma comunicação de marketing (BUHALIS \& VOLCHEK, 2020). O principal objetivo dessa ciência é desenvolver uma metodologia com o intuito de gerar inteligência sobre o valor que cada canal de marketing tem para o resultado de conversão ao 
longo da jornada do consumidor. Esse resultado permite uma análise do impacto dos pontos de contato de comunicação de marketing (que vamos nos referir como "canais") e, com isso, decisão fundamentada de alocação de investimento e seleção de canais visando a otimização do retorno sobre investimento em publicidade (ROAS - return on advertisement spend).

\subsection{Conceitos fundamentais}

\subsubsection{Comunicação e canais de marketing}

Segundo Kotler, comunicação de marketing é o meio pelo qual as empresas buscam informar, persuadir e lembrar os consumidores sobre os produtos e as marcas que comercializam (KOTLER \& KELLER, 2006). A comunicação de marketing pode contribuir tanto para reforçar a lembrança da marca na mente dos consumidores (share of mind) como para impulsionar as vendas. O ambiente de comunicação de marketing vem se transformando profundamente com a influência de novas tecnologias, novos formatos de consumo de conteúdo e a forma como os consumidores estão consumindo informações sobre produtos e marcas. O ambiente se caracteriza por uma maior diversidade de opções de mídia, bem como um consumidor mais seletivo se e como querem receber mensagens publicitárias. Nesse contexto, medir a performance de canais torna-se mais importante e desafiador à medida que cada consumidor interage com pontos de contato distintos onde a empresa pode e deve estar presente e a forma como cada indivíduo percorre a jornada de consumidor passa a ser rastreada e armazenada de forma barata pelas empresas.

\subsubsection{Canais de marketing iniciados pela empresa e pelo cliente}

Dada a definição de canal que será utilizada neste trabalho, uma outra terminologia se faz importante para a pesquisa de atribuição de marketing. A 
partir do agente que faz a mensagem aparecer, pode-se classificar os canais em dois tipos: canais iniciados pela empresa e canais iniciados pelo cliente. Canais iniciados pelo empresa incluem comunicações que a empresa inicia o processo de emissão da mensagem, como por exemplo: anúncios online, comerciais de TV, newsletter. Por outro lado, canais iniciados pelo cliente referem-se a comunicações que os consumidores iniciam o processo, como visita direta ao site da empresa, engajamento com mídias sociais, chat online.

Como o comportamento do consumidor é influenciado pelo seu estado atual de consciência, interesse e desejo em relação a um produto ou serviço, os pontos de contato possuem a tendência de produzirem efeitos diferentes dependendo da parte que iniciou a comunicação (BUHALIS \& VOLCHEK, 2020). Dessa forma, pesquisas demonstraram que, na atribuição de marketing, canais iniciados pelo cliente possuem uma contribuição significativa para o resultado final. Adicionalmente, estudos apontaram que canais iniciados pela empresa detém um papel-chave para engajar consumidores que ainda não conhecem a marca (ANDERL, SCHUMANN et. al, 2016; KIZGIN et. al, 2020).

\subsubsection{Efeitos de "carryover" e spillover"}

Seguindo a revisão de conceitos que circundam a pesquisa de atribuição de marketing, os efeitos podem produzir efeitos distintos sobre o resultado final de conversão, e isso deve ser levado em consideração nas decisões de alocação de orçamento e seleção do mix de mídias da empresa. A sequência de canais que o consumidor experiência na sua jornada de compra pode ter efeitos sinérgicos ou antagônicos na tomada de decisão de consumo, potencializando ou deteriorando o efeito da comunicação de marketing (NOTTORF, 2014; SINHA, MEHTA et al., 2015). Dependendo do estágio atual do consumidor na jornada de consumo daquela marca ou empresa, o efeito de um ponto de contato pode sofrer variações dependendo se houve ou não uma interação anterior com o mesmo contato ou outro ponto de contato. O efeito de "carryover" acontece quando essa sobreposição de efeitos ocorre entre o mesmo canal. Então, a repetição da interação do cliente com um canal pode fazer com que ele avance estágios na jornada na direção da conversão. Um exemplo é quando o cliente clica em duas sessões diferentes no anúncio de 
pesquisa de uma empresa procurando por um produto específico. De outra maneira, o efeito de "spillover" acontece quando a sobreposição de efeitos ocorre entre canais de marketing diferentes, fazendo com que a interação com um canal prévio intensifique e reduza o efeito do próximo canal. Pesquisas recentes concluíram que anunciantes tendem a supervalorizar a contribuição de canais engatilhados pela intenção do usuário (ABHISHEK, 2015), como anúncios de pesquisa.

\subsection{Tipos de Abordagens}

O tema da atribuição de marketing tem atraído cada vez mais atenção de pesquisadores, como Berman (2015) e Abhishek (2015). A maioria dos trabalhos desenvolvidos na área tem a intenção de propor um modelo analítico de atribuição que permita concluir que uma certa metodologia pode ser mais efetiva na mensuração de performance dos canais do que outra dado o contexto operacional da empresa. Acadêmicos propuseram uma grande variedade de modelos, no entanto até o momento da publicação desse estudo, não existe ainda um consenso sobre qual abordagem metodológica é a mais precisa (ZAREMBA, 2020).

A fim de facilitar a identificação das variadas abordagens exploradas pelos pesquisadores, elas são divididas em duas grandes categorias: as abordagens heurísticas (ou baseadas em regras ou arbitrárias) e as abordagens orientada por dados (ou algorítmicas). Essa taxonomia é facilmente visualizada no trabalho de Kannan e Zaremba. Ambos fazem uma revisão de literatura do tema e apresentam o estado da arte da pesquisa em modelo de atribuição. 
Tabela 1 - Categorias de Modelo de Atribuição

\begin{tabular}{|c|c|c|c|}
\hline Categoria & Tip & Modelo & Regras gerais \\
\hline \multirow{6}{*}{$\begin{array}{l}\text { Heurística } \\
\text { (crédito distribuído } \\
\text { arbitrariamente) }\end{array}$} & \multirow{3}{*}{ 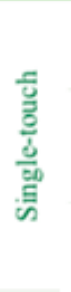 } & Último clique & O efeito geral para a conversão é atribuído ao último clique \\
\hline & & $\begin{array}{l}\text { Último clique } \\
\text { não direto }\end{array}$ & $\begin{array}{l}\text { O efeito total para a conversão é atribuído ao último clique que não foi y } \\
\text { Um acesso direto ao site. }\end{array}$ \\
\hline & & $\begin{array}{l}\text { Primeiro } \\
\text { clique }\end{array}$ & O efeito geral para a conversão é atribuído ao primeiro clique. \\
\hline & \multirow{6}{*}{$\frac{\text { 들 }}{\frac{3}{3}}$} & Linear & $\begin{array}{l}\text { O impacto para a conversão é atribuído proporcionalmente a cada } \\
\text { Ponto de contato no caminho até a conversão. }\end{array}$ \\
\hline & & $\begin{array}{l}\text { Baseado na } \\
\text { posição }\end{array}$ & $\begin{array}{l}\text { O efeito geral para a conversão é atribuido dependendo da posição do } \\
\text { ponto de contato no caminho até a conversão. Por exemplo, o Google } \\
\text { Analytics atribui como padrão } 40 \% \text { de impacto para o primeiro e o último } \\
\text { clique, e os } 20 \% \text { restantes são distribuídos proporcionalmente. }\end{array}$ \\
\hline & & $\begin{array}{l}\text { Peso } \\
\text { ponderado }\end{array}$ & $\begin{array}{l}\text { O efeito para a conversão é atribuido arbitrariamente e subjetivamente } \\
\text { para cada canal (frequentemente em conformidade com uma análise } \\
\text { prévia sofisticada) }\end{array}$ \\
\hline \multirow{3}{*}{$\begin{array}{l}\text { Algorítimica } \\
\text { (crédito distribuído } \\
\text { econometricamente) }\end{array}$} & & $\begin{array}{l}\text { Regressão } \\
\text { logística }\end{array}$ & $\begin{array}{l}\text { O efeito geral para a conversão é estudado com base na regressão logistica, } \\
\text { que consiste na decomposição de todos os caminhos de conversão e o } \\
\text { cálculo binário com ou sem a presenca de um certo canal no caminho. }\end{array}$ \\
\hline & & $\begin{array}{l}\text { Cadeia de } \\
\text { Markoy }\end{array}$ & $\begin{array}{l}\text { O efeito de canais para a conversão é determinado com base na análise do } \\
\text { impacto incremental que o canal tem em toda população. Baseado nos } \\
\text { caminhos de conversão, cadeias são criadas com a probabilidade do usuário } \\
\text { migrar de um canal para outro. Durante a análise canais individuais são } \\
\text { removidos e as probabilidades são avaliadas com a remoção daquela canal. } \\
\text { A diferença resultante é o impacto incremental que evidencia o impacto } \\
\text { real de um certo canal para a conversão final. }\end{array}$ \\
\hline & & $\begin{array}{l}\text { Valor de } \\
\text { Shapley }\end{array}$ & $\begin{array}{l}\text { A abordagem da teoria dos jogos e o método do valor de Shaplex são } \\
\text { formas de medir a contribuição marginal média de um canal para cada } \\
\text { conjunto de canais. A contribuição marginal de um canal particular é a } \\
\text { diferença média entre os resultados de conversão de conjuntos de canais } \\
\text { com e sem um determinado canal. } \\
\text { a parucuiar cnanneı. }\end{array}$ \\
\hline
\end{tabular}

Fonte: Zaremba (2020) adaptação nossa

\section{- Abordagem Heurística}

Embora o problema de atribuição seja um desafio antigo dos gestores de marketing, somente foi possível aprofundar os modelos de atribuição quando as mídias online passaram a rastrear através de compartilhamento de dados dos usuários a jornada de compra de cada consumidor. A combinação de big data de interação individual, quase que em tempo real e com um armazenamento de 
dados em nuvem a custo zero criou condições favoráveis para tornar a atribuição de marketing uma análise mais precisa e estratégica para as empresas. Com a disponibilidade de dados a nível individual do caminho de conversão de cada usuário com a identificação dos pontos de contato anteriores a qualquer evento de conversão, pensar a atribuição como uma escolha estratégica dos canais de marketing passou a ser não só mais viável, como cada vez mais importante (KANNAN, 2016).

A partir de meados de 2012, quando plataformas de dados (como o Google Analytics, que é de acesso gratuito) possibilitaram organizar de modo estruturado a jornada de cada usuário até a conversão em diferentes dispositivos e plataformas, muitas empresas começaram usando abordagem heurística de atribuição devido a falta de metodologias mais sofisticadas. Abordagens heurísticas consistem em regras com base na intuição da empresa de como cada canal atua no funil de conversão do consumidor (KANNAN, 2016).

O próprio Google Analytics possui uma funcionalidade de funil multicanal em que a empresa pode comparar como o resultado da conversão seria distribuído entre os canais a partir da escolha de uma regra de atribuição heurística.

Figura 1 - Ferramenta de Comparação de Modelos

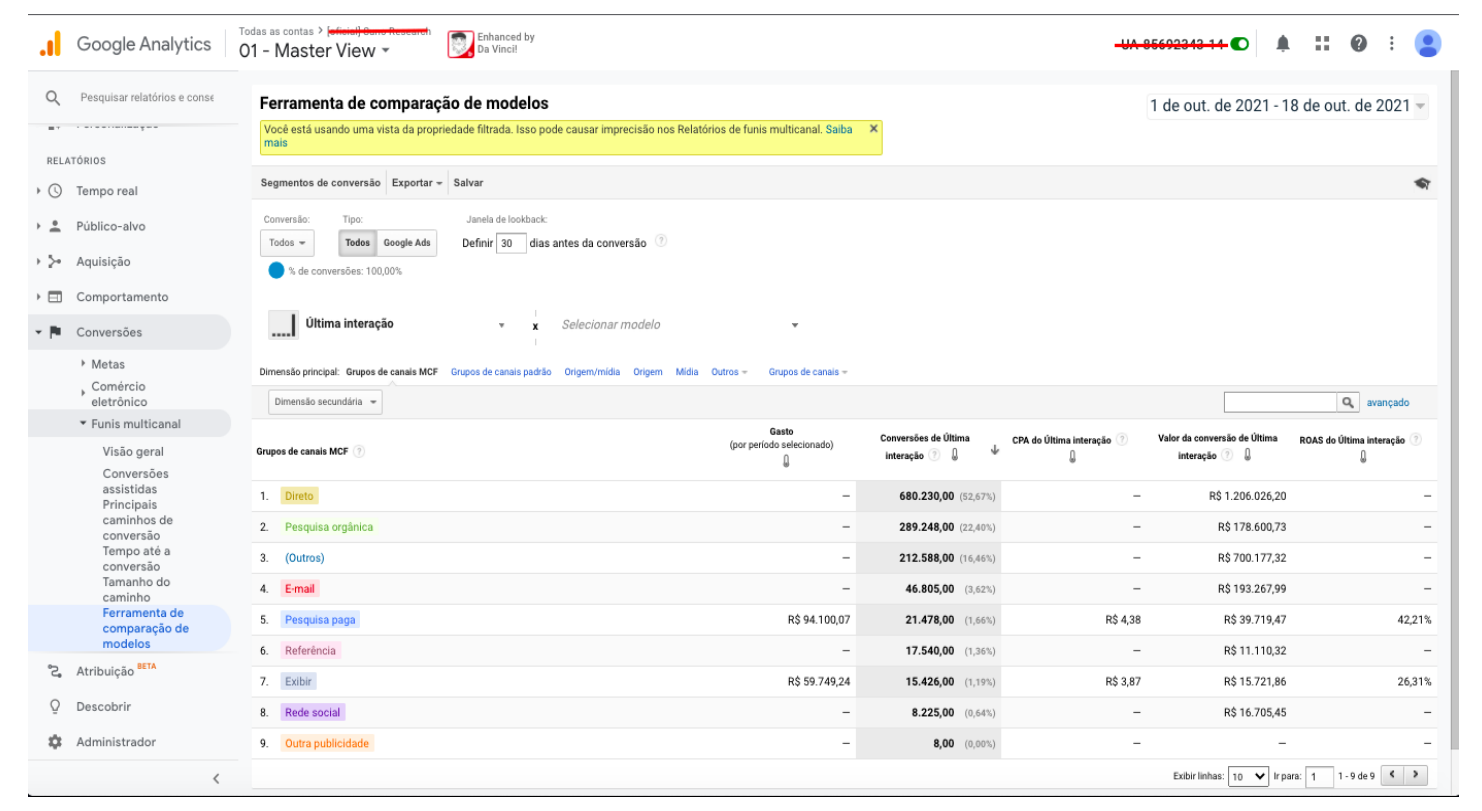

Fonte: do autor

São fornecidos ao todo sete modelos: 
No modelo de atribuição "Último Clique", o último ponto de contato recebe $100 \%$ do crédito de conversão.

No modelo de atribuição "Primeiro Clique", o primeiro ponto de contato recebe $100 \%$ do crédito de conversão.

No modelo de atribuição "Linear", todos os pontos de contato recebem o mesmo crédito assumindo que todos eles tiveram uma contribuição equivalente para fazer o usuário converter.

Último clique não direto: o último ponto de contato por meio do qual o cliente clicou, sem considerar o tráfego direto, recebe $100 \%$ do crédito de conversão.

Último clique do Google Ads: o último clique em alguma publicidade do Google Ads recebe $100 \%$ do crédito de conversão.

Redução de tempo: os pontos de contato mais próximos em termos de tempo da venda ou conversão recebem a maior parte do crédito

Com base na posição: com base na posição, a empresa escolhe o percentual de contribuição que o primeiro, o último e os canais do meio irão receber por uma conversão.

O modelo último clique é um dos mais usados na indústria por conta de sua conveniência e facilidade de implementação (ABHISHEK, 2015). A principal desvantagem do modelo é induzir as empresas a concluírem que anúncios que fizeram o consumidor ter seus primeiros contatos com o site da empresa em nada contribuíram para a conversão. Diversos estudos concluíram que a abordagem heurística leva, na maioria das vezes, os gestores a conclusões incorretas sobre a atribuição. (ABHISHEK et. al, 2015; LI \& KANNAN, 2014; XU et. al, 2014). 


\section{— Abordagem Orientada por Dados}

Com a evolução dos estudos sobre atribuição, metodologias mais robustas para medir a performance dos canais passaram a ser desenvolvidas nos estudos acadêmicos. A abordagem orientada por dados consiste em um método analítico que considera o histórico completo de interação dos usuários com os canais da empresa para calcular a performance de cada canal. $O$ problema da atribuição passa a ser percebido como um problema - cuja dimensão é proporcional ao valor investido em mídia online, em que as empresas necessitam realizar uma previsão mais acurada sobre quais são os caminhos mais utilizados pelos usuários até a compra, levando em consideração toda a complexidade da jornada multicanal do ambiente atual de comunicação de marketing. A precisão da atribuição é dependente da capacidade do modelo definido pela empresa de alocar valor aos pontos de contato em conformidade com o efeito real que os mesmos possuem na tomada de decisão (KANNAN et al., 2016; BUHALIS et. al., 2020). O valor de atribuição mais preciso deve ser derivado de todo escopo de comunicação de marketing que cada consumidor foi exposto ao longo da sua jornada de compra. Segundo Kannan et al., "o valor acurado de alocação deve ser atribuído para cada ponto de contato no contexto das especificidades de cada jornada do consumidor".

A implementação de um modelo capaz de usar os dados em tempo real para mostrar quais são os canais fundamentais para trazer uma conversão geram análises mais fiéis à realidade. Essa análises, por sua vez, fazem as empresas tomarem decisões sobre alocação de orçamento entre canais e seleção de mix de mídia para cada etapa do funil que vão potencializar o resultado final de ROAS (ANDERL, 2016).

Um ponto em comum entre as conclusões dos estudos acadêmicos e o conhecimento gerencial publicado em artigos de blogs e fóruns profissionais a respeito de modelos de atribuição consiste na ideia de que não existe o melhor modelo para se aplicar hoje. No episódio de podcast da empresa de educação de marketing Métricas Boss, a especialista em Data Analytics e Marketing de Performance, Marina Nauer, comenta que não existe o melhor modelo, mas sim aquele mais adequado para a realidade de negócio de cada empresa. $O$ estado da arte atual da pesquisa acadêmica mostra que as descobertas dos estudos 
sobre atribuição de marketing podem gerar insumo de conhecimento para anunciantes compreenderem como fazem a atribuição no momento presente e como poderiam redefinir sua mensuração de performance dos canais. No entanto, as pesquisas estão longe de concluir que existe um modelo que se demonstre unânime por sua eficiência, eficácia e facilidade de implementação.

Alguns estudos, como o de Dalessandro et al. (2012), pontuam características que modelos de atribuição adequados devem carregar:

- ser justo - todos os canais devem ser levados em consideração e mostrar seu impacto ponderado para a conversão final

- ser orientado por dados - o modelo deve ser construído com base nos objetivos de marketing, os estágios da jornada de consumo e dados reais gerados pelas campanhas

- ser fácil de interpretar - o modelo deve possuir regras intuitivas de se entender e ser amplamente aceito pelos profissionais envolvidos com a análise e otimização das campanhas

Danaher e van Heerde (2018) destacam cinco elementos de um bom modelo de atribuição:

- aumenta o efeito marginal de probabilidade de conversão de um canal

- pode gerar valor de zero se o canal não possui nenhum efeito para conversão

- é proporcional ao número de interações que o canal tem

- considera que o efeito de "carryover" existe

- reduz o resultado do canal aferido no modelo de último-clique quando não tem efeito de "carryover"

Há pesquisas que mostram que profissionais de marketing tendem a buscar e preferir soluções que permitam a criação de relatórios diários e que são baseados na gestão dia-a-dia do orçamento, como aponta Shao \& Li, 2011.

Apesar de toda tecnologia de infra-estrutura de coleta e armazenamento de dados disponível e da difusão de novos formatos de comunicação de marketing digital em plataformas e dispositivos diferentes, existem obstáculos que empresas enfrentam para rastrear a jornada digital de consumo de ponta a 
ponta. Essas barreiras consistem em regulações de proteção de dados privados, como histórico de busca e cookies. Além da barreira digital, existe obviamente dificuldades de mapear interações offline do cliente, como vista à loja física, e visualização de um outdoor na rua. Isso mostra que implementar um modelo apropriado à realidade da empresa não conseguirá descrever com 100\% de exatidão a contribuição de cada ponto de contato. $O$ intuito da atribuição de marketing é desenvolver um modelo justo, prático e que considere os canais de marketing mais relevantes para o consumidor mudar de estágio de envolvimento com uma marca ou um produto ou serviço.

\section{Métodos e procedimentos de coleta e análise de dados do estudo}

Neste capítulo serão apresentadas cinco sessões que demonstram os procedimentos de etapas de coleta de dados; as fontes de informações selecionadas para a coleta; os instrumentos e procedimentos de coleta usados no estudo; as formas de tratamento e análise dos dados coletados e as limitações do estudo, respectivamente.

\subsection{Etapas de coleta de dados}

Para este estudo foi feita uma pesquisa exploratória qualitativa que visa captar as percepções de gestores e profissionais de marketing no Brasil sobre o tema da atribuição de conversão. A partir de um roteiro de entrevista de nove perguntas o qual os entrevistados responderam por videoconferência, a pesquisa teve como objetivo entender qual a situação presente da atribuição de conversão nas empresas dos gestores entrevistados, qual a importância que é dada para esse assunto e os obstáculos que os gestores vivenciam na prática gerencial para mensurar a performance de marketing.

Para isso, a coleta de dados foi feita em duas etapas. Na primeira etapa foi realizada uma investigação preliminar do assunto com pesquisas realizadas em diversas regiões do mundo a respeito dessa experiência gerencial com 
atribuição de marketing. Esta primeira etapa teve como objetivo entender e mapear os principais obstáculos que aparecem nos estudos existentes para se implementar um modelo de atribuição eficaz. Essa etapa gerou implicações para se produzir o roteiro de perguntas que seria então aplicado nas entrevistas do estudo.

Na segunda etapa do estudo, foram conduzidas entrevistas pessoais com gestores, coordenadores e diretores de marketing de empresas com participação nos aspectos táticos e estratégicos de web analytics das empresas. As entrevistas foram feitas por videoconferência de forma síncrona e seguindo um roteiro de nove perguntas subjetivas.

\subsection{Fontes de informação selecionadas para coleta de dados no estudo}

Foram consideradas para a etapa preliminar do presente estudo informações obtidas em pesquisas semelhantes realizadas em outras regiões do globo, artigos científicos variados, palestras e episódios de podcasts sobre o tema com o intuito de investigar o conhecimento geral sobre o tema.

$\mathrm{Na}$ segunda etapa do estudo, foi selecionada uma amostra não probabilística de 5 pessoas pelo critério de amostragem por julgamento, onde o pesquisador busca por indivíduos que possuem características definidas previamente para sua amostra (GIL, 2008). Este critério é aceito em estudos exploratórios uma vez que não exige elevado nível de precisão. Os indivíduos foram selecionados por se enquadrarem no perfil.

\subsection{Procedimentos e instrumentos de coleta de dados utilizados no estudo}

$\mathrm{Na}$ segunda etapa da pesquisa exploratória, os principais dados foram coletados através de entrevistas individuais e pessoais. Neste caso, o investigador se apresenta frente ao investigado e lhe formula perguntas com o 
objetivo de obter dados pertinentes à investigação (GIL, 2008).

Desta forma, cada entrevista foi realizada individualmente, com base em um roteiro de perguntas semiestruturadas (Apêndice 1) para que os entrevistados pudessem falar mais livremente sobre os assuntos abordados. Os participantes foram questionados sobre a forma como é feita a mensuração de conversão na empresa onde trabalham, qual modelo de atribuição utilizam atualmente e, para aqueles que não possuem um modelo sofisticado de atribuição, os motivos pelos quais não implementam tal modelo e quais desafios enfrentam para implementar uma atribuição mais eficaz e eficiente na empresa.

A intenção das perguntas foi captar um panorama o mais verossímil possível ao que os tomadores de decisão e analistas de marketing de empresas pensam e vivenciam a respeito do problema da atribuição nas suas experiências gerenciais. As entrevistas, com duração média de 40 minutos, foram realizadas por videoconferência de forma síncrona durante o mês de outubro de 2021 , de acordo com a disponibilidade de cada participante.

\subsection{Formas de tratamento e análise de dos dados coletados para o estudo}

$\mathrm{Na}$ análise de dados de uma pesquisa qualitativa o foco é principalmente a exploração do conjunto de opiniões sobre o tema investigado, identificando os diferentes grupos homogêneos de opiniões e crenças dentro da amostra analisada (BAUER e GASKELL, 2017). Deve-se identificar não só o que há de homogêneo como aquilo que se diferencia dentro daquele meio social.

Para a realização desta análise foram aplicados os procedimentos de categorização, inferência, descrição e interpretação dos dados conforme procedimentos metodológicos identificados por Bauer e Gaskell (2017), classificando as respostas obtidas em categorias exclusivas e exaustivas.

A definição de categorias foi desenvolvida a partir de hipóteses inferidas dos estudos da etapa preliminar de coleta de dados. Contudo, a partir das entrevistas, foram adicionadas hipóteses que não foram encontradas nas pesquisas da etapa preliminar da coleta de dados e que mostraram relevância no contexto dos entrevistados. 


\subsection{Limitações do estudo}

O estudo prevê limitações sobre o resultado obtido, que são naturais do caráter metodológico empregado. As limitações fazem com que o resultado não seja estatístico e, consequentemente, não possa ser generalizado. Como a pesquisa foi feita com 5 gestores, existe uma limitação de volume de respostas do estudo.

As conclusões aqui obtidas pretendem aprofundar o tema da atribuição de conversão na literatura nacional e trazer melhor visão sobre os principais obstáculos que profissionais de marketing no Brasil enfrentam nesse aspecto. Já que o tema pesquisado possui pouco material produzido a seu respeito considerando o contexto brasileiro de marketing, torna-se difícil formular hipóteses precisas, sendo, portanto, necessário conduzir uma pesquisa exploratória. (MALHOTRA, 2011).

Por meio de estudo exploratório, esse estudo se propõe, por meio de roteiro semiestruturado de perguntas, a mapear os principais obstáculos e dificuldades que gestores de marketing digital vivenciam nas suas empresas para atribuir $o$ resultado entre seus canais de marketing. $O$ grande questionamento é iniciar uma investigação a respeito do que impede os gestores de aplicar um modelo de atribuição e fazer uma mensuração de performance de marketing de modo mais realista, orientado por dados e em linha com a jornada de consumo atual de múltiplos pontos de contato. Apesar das limitações do método de coleta de dados do estudo, as informações coletadas com as entrevistas permitem traçar um panorama inicial das dificuldades vivenciadas pelos gestores em atribuição de conversão.

\section{Apresentação e análise dos resultados}

Este capítulo apresentará os dados coletados na pesquisa realizada através de entrevistas pessoais com o público alvo.

Serão apresentados cinco grupos de informações coletadas, separadas de acordo com o objetivo de cada etapa. O primeiro grupo de informações refere-se ao perfil dos participantes. O segundo, à situação atual do modelo de 
atribuição das empresas dos gestores participantes. O terceiro, aos tipos de análises realizadas por cada um dos gestores para fazer o planejamento de investimento e seleção de canais de marketing. $O$ quarto, é referente às dificuldades e desafios enfrentados pelos participantes para medir o desempenho de marketing. Por último, uma análise comparativa das respostas observadas.

Os dados das entrevistas foram gravados, transcritos para então serem separados em categorias. Dentro de cada grupo os dados foram categorizados para que pudessem ser feitas as análises dos mesmos e identificados pontos homogêneos e heterogêneos, assim como desafios existentes para o futuro da atribuição de conversão.

\subsection{Perfil dos participantes entrevistados}

O grupo de entrevistados foi composto por 5 pessoas selecionadas por julgamento dentro do perfil de público que esse estudo propõe investigar: gestores, diretores e coordenadores de marketing com participação direta nas análises e tomadas de decisão de otimização de performance de marketing digital em empresas que investem pelo menos mais de $R \$ 100$ mil reais em mídias digitais por mês. O perfil dos entrevistados pode ser observado na tabela 2 abaixo, na qual os nomes dos entrevistados e das empresas onde trabalham foram ocultados para manter sua privacidade e sigilo das informações compartilhadas.

Tabela 2 - Perfil dos participantes das entrevistas pessoais

\begin{tabular}{|l|l|l|l|}
\hline & Cargo na empresa & Tipo da empresa & $\begin{array}{l}\text { Faixa de investimento } \\
\text { mensal em mídias (R\$) }\end{array}$ \\
\hline Entrevistado 1 & $\begin{array}{l}\text { Coordenador de } \\
\text { Web Analytics }\end{array}$ & Banco digital & 1 milhão - 1,5 milhão \\
\hline Entrevistado 2 & Gerente de Mídias & Empresa de serviços & 300 mil - 500 mil \\
\hline
\end{tabular}




\begin{tabular}{|l|l|l|l|}
\hline & Pagas & de investimentos & \\
\hline Entrevistado 3 & $\begin{array}{l}\text { Analista de Web } \\
\text { Analytics }\end{array}$ & $\begin{array}{l}\text { Empresa de beleza } \\
\text { e cosméticos }\end{array}$ & 1 milhão - 1,5 milhão \\
\hline Entrevistado 4 & Diretor Geral & $\begin{array}{l}\text { Empresa de serviços } \\
\text { de investimentos }\end{array}$ & 300 mil - 500 mil \\
\hline Entrevistado 5 & Diretor Geral & $\begin{array}{l}\text { Consultoria de } \\
\text { marketing }\end{array}$ & 300 mil - 500 mil \\
\hline
\end{tabular}

Fonte: do autor

\subsection{Situação atual de modelo de atribuição}

Com o objetivo de validar a participação dos entrevistados na pesquisa, e também compreender o estágio atual em que a empresa da qual o(a) participante atua como gestor(a) de marketing se encontra no que se refere a atribuição de marketing, os entrevistados foram perguntados como mediam as conversões e o retorno sobre o investimento em cada canal de marketing. Foi perguntado também qual modelo de atribuição o(a) gestor(a) utiliza no presente para medir as conversões dos canais da empresa. Além disso, avançando para um aspecto mais técnico, foi perguntado se a plataforma de mensuração utilizada era o Google Analytics, qual o modelo definido dentro da plataforma e se o(a) gestor estava satisfeito com a sua mensuração de resultados no presente momento.

Estas informações, em conjunto, ajudam a criar um panorama geral do estágio atual de atribuição de conversão da empresa do(a) gestor(a) entrevistado(a), sugerindo suas percepções, opiniões e objeções que serão investigadas posteriormente.

\subsubsection{Métodos e plataformas para medir conversão}

Todos os 5 participantes da pesquisa tinham o conhecimento para dizer como funcionava a mensuração de conversão nas empresas em que trabalham. Foi possível observar aspectos homogêneos e heterogêneos nas respostas dos participantes. Daqueles que mais mostraram certeza para explicar como a 
mensuração de conversão acontecia no negócio, a resposta foi que eles utilizam a plataforma do Google Analytics, responsável por captar os sinais de conversão e navegação, integrado com um banco de dados externo e isso acaba configurando um modelo de atribuição. Esses participantes compartilham algo em comum no perfil de profissional de atuar no aspecto mais estratégico do planejamento de marketing.

Os demais entrevistados, ainda que tenham compartilhado com convicção o modelo de mensuração da sua empresa, mencionaram todas as formas possíveis para medir a conversão da empresa, não destacando o modelo principal usado para desdobrar metas e indicadores de performance para o negócio. Desses a resposta foi que utilizam também o Google Analytics e comparam com os valores de conversão mensurados por plataformas de mídias pagas. Com isso, afirmaram que podem avaliar se existe discrepância nos números aferidos e investigar qualquer anomalia comparando com o resultado consolidado da empresa.

"Eu acabo utilizando o Google Analytics pra ver as conversões de receita mas eu sempre comparava com as ferramentas de mídia para ver como que estava essa discrepância porque a discrepância sempre vai ter. Porque as ferramentas, elas medem de formas diferentes. Só que dependendo do quanto é essa discrepância algo precisa ser investigado." (Entrevistado 1)

Algumas vezes foi apontada a necessidade de medir a conversão considerando as regras de negócio da empresa, isto é, levando em consideração o valor de receita que realmente é registrado na conta de receita do demonstrativo financeiro da empresa.

"Então a gente tem $100 \%$ preciso no banco de dados mas, no dia a dia, assim o Analytics ajuda a dar um bom cheiro do que do que está acontecendo com o nosso desempenho." (Entrevistado 4)

\subsubsection{Formas de medir o retorno sobre o investimento em marketing}

Nessa questão que acabou sendo abordada em diferentes perguntas da entrevista, todos os entrevistados deram sua resposta ponderando que talvez o 
modelo utilizado não seja o mais preciso possível. Isso é reforçado pelo fato das respostas terem tido poucos pontos semelhantes na construção da explicação sobre a forma de medir. Um entrevistado destacou que esse tipo de análise depende do objetivo de campanha e de que algumas campanhas realmente não são feitas para trazer retorno financeiro para a empresa. Contudo, como mesmo foi apontado na resposta, no momento de compartilhar resultados com diretoria de alto escalão, essas campanhas não focadas em gerar receita diretamente são avaliadas por outros resultados, como visitas no website, número de pessoas alcançadas, visitas em páginas de venda, e etc.

"O que eu costumava fazer para medir o impacto de resultado, como geralmente diretores e superintendentes, eles entendem mais número e de receita, é óbvio que você vai trazer então ROI - você vai dividir o quanto foi investido e dividir pela receita. Mas se você só reportar isso, é muito pobre." (Entrevistado 1)

"No funil, eu trazia o objetivo de cada canal também. No Facebook a gente tinha na verdade um objetivo de awareness. então olha quantas visitas, olha como a gente aumentou brand lift, Olha como a gente aumentou o nosso alcance; olha como aumentar o nosso alcance contribuiu pra gente aumentar a receita nesse mês. Então eu trazia essas outras informações mais como análise do que de fato métrica. Como eu falei os ambientes eles são muito pobres nesse sentido para você trazer uma coisa mais algorítmica. Acaba vindo como insight mesmo separado por objetivo do funil." (Entrevistado 1)

Uma linha de explicação por outros entrevistados buscou salientar que a forma de medir da empresa considera o investimento real, que saiu do caixa, e o retorno real, que entrou no caixa da empresa. Isso sugere que a análise do retorno do investimento em mídias digitais deve passar necessariamente, no caso da empresa do entrevistado, por um banco de dados que valida as transações financeiras realizadas.

Em relação a forma de medir conversão, é possível agrupar as respostas em duas categorias: métodos que consideram a receita observada na plataforma de web analytics (métodos de analytics) e métodos que consideram a receita real observada no caixa da empresa (método financeiro).

Um dos pontos que mais sobressaíram nas respostas fornecidas foi 0 Entrevistado 4 que comentou sobre a forma como se mensura o desempenho 
das campanhas na sua empresa através da visão por safra: "Uma coisa que a gente avalia aqui e que talvez se a gente usasse um modelo de atribuição a gente não tivesse conseguido desenvolver, ver o ROAS por por campanha e por safra. Por exemplo, em mídia paga [...] a gente vai olhar a safra e vai olhar a campanha de cada um dos leads que a gente gerou e ver eventualmente em quanto tempo esse lead vai converter para que para essa safra tenha um ROAS positivo."

As respostas dos entrevistados foram bem heterogêneas, porém pode-se observar que todos os entrevistados nas suas realidades de empresa levam em consideração os sinais de Analytics junto com as transações reais registrada pelo caixa da empresa. O que parece que muda é, em uma análise em uma base diária, algumas entrevistados aparentam estar distantes da visualização dos dados financeiros da empresa e acabam, por isso, somente consolidando os resultados mensurados pela plataforma de Analytics.

Através das respostas vemos uma tendência dos gestores de marketing em se atentarem a importância de possuir um ambiente de web analytics bem implementado e a necessidade de evoluir no futuro para um modelo de atribuição dentro do Google Analytics que considere a contribuição de canais não são o último clique da conversão.

"Todos eles têm impacto positivo, então a gente acaba vendo de maneira geral last-click. Não chegamos a aprofundar assim sabe? Se eu tô falando de atribuição, como que cada canal impacta no funil... a gente não vai a isso. Eu acho que a gente deve em algum momento em breve mas hoje a gente acaba olhando é de outras em outros formatos." (Entrevistado 4)

\subsubsection{Modelo de atribuição utilizado}

Todos os entrevistados falaram que utilizam o modelo último clique para medir conversões. Em nenhuma resposta, foi observado que um modelo de atribuição multi-touch é usado ou mesmo que tem projeto factíveis de ser implementado. 


\subsection{Tipos de análises feitas para fazer o planejamento de investimento e mix de mídias}

Nesta etapa da pesquisa foram feitas perguntas para compreender quais são as premissas e métodos de análises que são feitos para gerar implicações para o planejamento de investimento e seleção de canais no médio e longo prazo.

As respostas dos entrevistados, embora possuam diversos aspectos divergentes, apresentaram pontos de intersecção. Desconsiderando os modelos de negócio e a jornada de consumo de cada empresa, todos os entrevistados, com exceção do Entrevistado 4, destacaram a necessidade de frisar que nem toda campanha tem o objetivo de gerar receita (ou ROAS, como é frequentemente falado no mercado) e, por isso, cada campanha deve ser analisada a partir do objetivo de marketing que ela possui. Nesse sentido, o Entrevistado 1, o Entrevistado 2 e 0 Entrevistado 3 comentaram coincidentemente sobre o desafio que é dar transparência sobre o resultado de certos tipos de campanhas que não geram ROAS na atribuição "last-click".

"... o grande desafio acaba sendo: como justificar e dar a transparência do resultado de ações que não trazem resultado de imediato. Por exemplo, uma campanha pra gerar tráfego ou visualização de vídeo. Ela não traz retorno direto pra empresa. Se olharmos com esses olhos, isso gera uma insustentabilidade para a estratégia. $O$ desafio é conseguir associar as variadas estratégias com as métricas que são devidas para aquele tipo de resultado." (Entrevistado 2)

O Entrevistado 1 e o Entrevistado 3 mencionaram essa necessidade também em suas respostas e ainda acrescentaram que parte da responsabilidade de comunicar a importância de campanhas com diferentes objetivos é do próprio gestor responsável pela execução da estratégia de mídia e análise de resultados. Nesse sentido, através das respostas, dois pontos aparecem como um desafio para se implementar um modelo de atribuição mais multitouch: a habilidade dos profissionais de web analytics de comunicar os resultados de campanhas em todas as etapas do funil.

"Quando você fala com um gerente que está vendo uma apresentação, acaba que a pessoa não vê muito valor naquilo. $A$ maneira de mostrar a importância e pegar atenção do público 
para ele ver que aquilo faz sentido. Falta um pouco para os profissionais tomar um cuidado na hora da apresentação, treinar, explicar por que mensurar o modelo de atribuição e ver qual o canal que trouxe a conversão e que cada um tem a sua importância." (Entrevistado 3)

"A média gestão, os gestores de marketing, eles entendem as coisas que estão sendo faladas. Quando o profissional de marketing for reportar para o gerente dele ou um superintendente de vendas, eles não entendem essas métricas, eles não entendem o que significam essas coisas." (Entrevistado 1)

A partir dessas respostas vemos que talvez exista uma certa lacuna organizacional em algumas empresas entre os profissionais que implementam a estratégia de marketing digital e os gestores/diretores que aprovam e garantem o orçamento dessas estratégias. Se um certo grupo de campanhas não gera conversão, porque deve-se seguir investindo nelas? Qual é o racional que garante que existe uma relação entre esse investimento e o retorno geral do marketing da empresa? Esses são alguns questionamentos implícitos que podem aparecer durante a comunicação dos resultados de marketing digital.

No sentido contrário, o Entrevistado 4, que é diretor geral e assume exatamente essa função de avaliar os resultados e aprovar orçamento, entende que, no modelo "last click" utilizado pela empresa hoje, é impossível medir o resultado incremental dos canais. Segundo ele: "O que a gente faz é confiar que ele existe; e obviamente ele existe." O diretor, que avalia o desempenho dos canais por meio de uma visão de safra de lead, reconhece que não possui um modelo de atribuição que pudesse gerar o impacto que cada canal teve em cada etapa do funil, mas afirma que está satisfeito com o modelo de safra desenvolvido pela empresa até então. De uma forma geral, o modelo consiste em mensurar os resultados com um banco de dados externo integrado ao Google Analytics e que contabiliza todas as conversões de último clique com o número de identificação único da venda real transacionada no banco de dados. Com isso, o banco de dados associa àquela venda real uma origem e uma mídia de algum canal e também se aquela transação tiver sido de um contato do CRM quando que esse contato foi registrado e por qual canal esse usuário se tornou um lead.

"Então eu acho que o fato da gente ver safra por safra no last-click, tipo a pessoa vem pela safra depois comprou. Isso ajuda bastante a gente." (Entrevistado 4) 
O grande ponto que diverge das percepções dos Entrevistados 3 e Entrevistados 1 a respeito da dificuldade que pode ser explicar para um diretor estratégico a importância de campanhas que não geram receita no último clique é que o diretor entrevistado é totalmente consciente sobre essa miopia existente no seu modelo de atribuição. Ele afirma que: "No nosso modelo todos os canais são importantes. A gente dificilmente desprioriza algum completamente porque ele não está trazendo receita last click, etc. [...] Então a gente não mede exatamente o impacto de cada funil".

\subsection{Principais dificuldades e desafios}

Com a intenção a real percepção dos gestores sobre as dificuldades que enfrentam ou enfrentaram para chegar no seu modelo de atribuição atual, três perguntas foram feitas de forma a provocar os entrevistados de diferentes maneiras. A primeira foi quais são as principais dificuldades vivenciadas para fazer o planejamento de orçamento e a seleção de canais para os próximos meses. Depois, foi perguntado quais são os desafios percebidos pelo(a) gestor(a) como oportunidade para otimizar o investimento em marketing. Por último, foi perguntado na experiência quais foram os principais obstáculos que o gestor(a) enfrentou e os que ele segue enfrentando para implementar um modelo de atribuição eficaz e eficiente.

De acordo com as respostas fornecidas, foi possível encontrar algumas categorias comuns de obstáculos e desafios. No aspecto de dificuldades, foram captadas as seguintes categorias: (i) falta de maturidade técnica e de implementação, (ii) habilidade comunicação dos times técnicos para alinhar a mensuração de resultados de campanhas que não trazem resultado no último clique , (iii) falta de prioridade para a realidade presente da empresa, (iv) outras dificuldades.

Na categoria "maturidade técnica", foram agrupados os comentários que destacaram que antes de se pensar em desenvolver um modelo de atribuição mais robusto, é preciso garantir um ambiente de implementação de eventos de web analytics bem consolidado, de forma que todas interações dos usuários com as campanhas captem os sinais corretos de conversão que precisam ser captados em cada fase da jornada de consumo, tratada sempre como um funil 
pelos entrevistados. O Entrevistado 1 comenta que a empresa ainda precisa evoluir muito em questão de garantir que os dados estão sendo coletados corretamente pela plataforma de Analytics.

"Você tem toda a coleta e precisa garantir que os dados estão corretos, implementar primeiro as coisas, ter uma base para trabalhar para daí você pensar até dados históricos para você começar a pensar num modelo de atribuição. Tem que olhar o seu histórico e entender percentualmente qual foi o impacto de cada mídia, de cada tipo de mídia naquela conversão. Então eu acho que precisa de tempo e todo esse processo é uma coisa que demora pra ser feito." (Entrevistado 1)

O Entrevistado 2 e o Entrevistado 4 dividem que ainda sentem uma lacuna considerável na operação das plataformas, quer por não sentir que o time é totalmente especializado nas plataformas para otimizar as campanhas o máximo possível, quer por perceber que a área ainda não executa uma estratégia "robusta" de mídia. O Entrevistado 2 considera estar executando e monitorando uma estratégia robusta um pré-requisito na questão de otimizar investimento: "Então, a gente está falando de uma atuação multivariada, com diversos objetivos de campanha, e o grande desafio acaba sendo: como justificar e dar a transparência o resultado de ações que não trazem resultado de imediato".

O Entrevistado 4, por sua vez, comenta que o seu principal desafio é "como eu consigo criar um time que seja especializado nas plataformas, desde de pensar em peças para as plataformas, testes etc, a ponto de otimizar o máximo possível essas campanhas que eu falei". O Entrevistado 4 se mostra confiante em relação ao modelo de atribuição desenvolvido até então, mas insiste em dizer que, dado esse modelo por meio do qual se mensura o ROAS, o que ele precisa ver é campanhas que atinjam o retorno o mais rápido possível com base na sua curva de conversão. Levando isso em conta, uma das dificuldades então consiste em capacidade técnica e especialidade do time que opera as plataformas.

$\mathrm{Na}$ categoria "habilidade de comunicação", foram agrupadas as respostas que mencionaram que uma das dificuldades para se discutir um modelo mais sofisticado de atribuição é a linguagem que os gestores que executam a estratégia de mídia comunicam com os diretores de alto escalão para compartilhar os resultados. O Entrevistados 1 e o Entrevistado 3 comentam 
que o profissional de analytics precisa ser capaz de traduzir todos aqueles dados visualizados nos painéis de conversão comparando o resultado por diferentes modelos de atribuição e aterrissar em uma conclusão que faça sentido direto para diretores que estão preocupados com a saúde financeira do negócio. Para o Entrevistado 1 isso acaba se tornando um grande desafio dentro da sua empresa: "É preciso ter essa comunicação com o gestor... fazer os superintendentes e diretores que não têm conhecimento técnico entenderem porque isso [estudo da atribuição] é importante.". O Entrevistado 3 faz um comentário na sua resposta muito semelhante: "Eu acho que sim [a estrutura organizacional da empresa influencia], mas o que eu acho que o pessoal de analytics deve ter cuidado é como mostrar a importância disso."

A categoria "falta de prioridade" reuniu comentários dos entrevistados em que eles salientam que evoluir o modelo de atribuição da empresa no momento presente não está dentro das prioridades da direção estratégica.

"Se for entre levar isso pro Analytics ou levar algum tipo dessa análise [de safra por safra] pro Analytics [...] e ter algum tipo de atribuição lá, isso é zero prioridade hoje. A gente tem um modelo que está minimamente desenhado e que funciona bem para o nosso negócio no estágio atual. O próprio passo não é prioridade no momento." (Entrevistado 4)

"A primeira é a questão da prioridade. Esse assunto é super relevante, mas diante dos outros, na fase em que a empresa esteja, talvez tenha menos prioridade." (Entrevistado 2)

Outras dificuldades foram classificadas em uma categoria separada por terem sido mencionadas de forma geral ou de forma extremamente específica em uma eventualidade do passado que não pode ser replicado para outros casos. As respostas completas, na íntegra, estão no apêndice 1 para consulta. Essas dificuldades faladas foram a falta de conhecimento técnico geral sobre atribuição de gestores da empresa e fatores exógenos que influenciam o desempenho das campanhas - como um termo que passa a ser buscado com muita frequência no Google devido a um evento momentâneo.

\subsection{Análise comparativa das respostas observadas}

Após a realização das respostas, foram identificados pontos em comum 
presentes na maioria das percepções dos gestores das empresas e pontos únicos da realidade de cada gestor na sua empresa. É possível identificar que todos os entrevistados, de certa forma, comentam que o projeto de atribuição para uma empresa acaba ficando de fora das principais prioridades da área de marketing. Isso pode ser explicitamente observado nas respostas dos Entrevistados 1, 2 e 4.

"Então eu acho que precisa de tempo e todo esse processo é uma coisa que demora pra ser feito. Eu só vi isso ser feito em um case sinceramente todos os meus anos." (Entrevistado 1)

Um ponto interessante que apareceu, não em todas, mas nas respostas de três entrevistados foi a dificuldade de alinhamento e comunicação com a gestão de alto escalão a respeito do que os dados de atribuição significavam para o negócio. Pode-se perceber que algumas empresas pautam grande parte das suas decisões de marketing nos resultados coletados pela plataforma Analytics (como o Google Analytics), enquanto outras submetem toda a sua decisão em análises sobre o resultado real de transações financeiras gerado pelos canais. Nesse caso os números de Analytics servem apenas para prover um indício ("dar um cheiro") sobre a performance dos canais.

Em contrapartida, alguns pontos específicos da situação de cada gestor apareceram ao analisar as respostas e podem servir como implicação para gestores refletirem sobre possíveis soluções e pesquisadores usarem tais assuntos como tema de estudo. Desses pontos específicos, podemos citar a dificuldade de recrutar profissionais capacitados de Web Analytics (mencionado pelo Entrevistado 1); a estrutura organizacional da empresa do Entrevistado 3 que divide o time de mídia em equipes por linhas de produtos, mesmo que vendidos no mesmo site; a complexidade de associar o custo de vários pontos de contato a um único lead, comentado pelo Entrevistado 4 como o próximo passo para evolução da análise de performance de marketing.

Por último, com o objetivo de entender o quanto os entrevistados percebem valor da inteligência gerada por um modelo de atribuição, perguntou-se quais os benefícios que teriam ao analisar os resultados com esse modelo. Todos os entrevistados emitiram uma resposta positiva e completaram que esse seria o mundo ideal. O Entrevistado 4 chegou até a desconfiar e 
comentou que ele acha que chegar nesse nível de mensuração de resultado é impossível de acontecer.

"Você vai colocar uma série de coisas que talvez não sejam reais. É uma tentativa e erro que vai e eventualmente atribuição é 100\% discricionário assim. Eu escolhi esse e aí seja o que Deus quiser. Você não vai encontrar ninguém falar tipo que esse é o melhor modelo de atribuição do mundo e que ele funciona $100 \%$. Você vai escolher aqueles que menos te dá problema. Então isso é impossível mas eu gostaria que fosse possível. É basicamente você ter uma marionete nas mãos, você vai saber exatamente como o seu retorno vem. E aí você vai poder direcionar os seus investimentos e o seu mix de forma perfeita." (Entrevistado 4)

No final, o desafio de toda área de marketing digital é buscar justificar para si mesmo que aquele investimento está trazendo o máximo de retorno possível. No mundo digital, as interações dos usuários passaram a ser cada vez mais rastreadas, mas recentes leis de proteção de dados estão atuando para limitar o poder que os publishers têm de oferecer esses dados aos anunciantes. Mesmo assim, os usuários, aceitando compartilhar suas informações de navegação na Internet, oferecem às empresas a possibilidade de entender quais são os principais caminhos de navegação até chegar no fim da jornada na conversão final. Ao longo de todos esses pontos, alguma inteligência deve buscar distribuir pontos de conversão de forma justa e orientada por dados. Esse é o sonho, mas parece que as áreas de marketing ainda têm muito a percorrer até conseguir consolidar esse projeto de atribuição.

\section{Conclusões e recomendações de novos estudos}

Esse estudo contribui para mapear obstáculos e desafios que impedem profissionais de marketing no Brasil de implementar um modelo de atribuição capaz de gerar mais inteligência sobre a jornada de conversão de múltiplos pontos de contato.

A revisão de literatura de atribuição de conversão mostra que ainda não existe um consenso sobre o método que mais ajude os gestores a otimizar as suas ações de marketing. Porém, as pesquisas e o interesse do mercado sobre 
o assunto da atribuição de conversão têm crescido nas últimas duas décadas (ZAREMBA, 2020) e, com isso, algumas conclusões com implicações gerenciais importantes têm se consolidado. Modelos "single-touch", que atribuem a conversão para um único ponto de interação do usuário levam a gerência de marketing a tomar ações que não otimizam o ROAS (retorno sobre investimento em marketing) (ABHISHEK, 2015). No mesmo sentido, modelos de atribuição heurísticos, baseados em regras arbitrárias definidas pela empresa, tendem a subvalorizar canais iniciados pela empresa, enquanto os canais iniciados pelo cliente são supervalorizados pela abordagem de último clique e primeiro clique (ANDERL, 2016).

Estudos como o de Dalessandro et al. (2012), pontuam características que modelos de atribuição eficientes devem carregar, como (i) ser justo, (ii) Ser orientado por dados e (iii) ser fácil de interpretar. As pesquisas sobre atribuição de conversão possuem o objetivo de desenvolver métodos que possam servir de suporte para a gestão de marketing aplicar na prática.

Com o objetivo de identificar dificuldades enfrentadas por diretores, gestores e coordenadores de empresas que possuem um investimento em larga escala (a partir de 100 mil reais por mês) em mídia online, essa pesquisa selecionou gestores dentro desse público e conduziu entrevistas pessoais com nove perguntas (ver Apêndice 1).

Através das entrevistas, foi possível identificar padrões de respostas que sugerem um mesmo tipo de dificuldade para se evoluir para um modelo de atribuição mais robusto do que o usado hoje. Em todas as entrevistas, a questão da prioridade foi mencionada como um motivo pelo qual a empresa não aprova projetos para implementar o modelo de atribuição. Os entrevistados pontuaram questões diferentes e específicas de cada empresa para isso, mas no geral admitem que fazer atribuição de um jeito diferente do que se faz no presente é algo que não é percebido como uma necessidade hoje. De modo semelhante, algo que apareceu muito nas respostas foi que os dados financeiros gerados pelas transações da empresa e os sinais de web analytics possuem muita divergência e isso acaba sendo uma dificuldade na atribuição de performance. Portanto, nesse sentido, mensurar o desempenho dos canais, na visão dos gestores entrevistados, é um exercício constante de comparação entre os valores de resultados que são obtidos no sistema financeiro e na plataforma de analytics da empresa. 
Por uma outra ótica, algo que sobressaiu em grande parte das entrevistas foi a falta de conhecimento e maturidade técnica do time operacional para planejar mudanças de modelo de atribuição. O ambiente de marketing digital, além de ser extremamente dinâmico, carece de profissionais capacitados e experientes em web analytics. Uma das respostas destacou a dificuldade de recrutar para essas vagas, enquanto outra pontuou que o principal desafio da área é formar um time especializado nas plataformas para otimizar o máximo possível o desempenho das campanhas. Diante disso, a propagação do conhecimento técnico sobre atribuição de marketing nas empresas se mostra como um dos requisitos para que as empresas consigam evoluir seus modelos de atribuição.

Devido a limitações de alcance de mais gestores responsáveis pela estratégia de mídia de empresas com um razoável investimento no digital, é possível que existam outras dificuldades consistentes nas empresas que não foram captadas aqui por esse trabalho. $O$ mapeamento feito por essa pesquisa estimula outros estudos para entender um dos principais motivos mencionados nas entrevistas: por que a atribuição acaba não sendo prioridade para a maioria das empresas. Na mesma linha de investigação, seria interessante também entender o tamanho do impacto que seria um negócio utilizar um modelo de atribuição multi-touch e personalizado com a sua realidade de negócio. Expor como decisões de marketing seriam diferentes se uma empresa medisse o resultado por um modelo linear contra um modelo de último clique, por exemplo, proporcionaria uma visão prática do impacto do modelo de atribuição para os profissionais da área. Os próximos estudos devem entender não só a ciência por trás de atribuição, mas como esse desafio está diretamente relacionado com as tomadas de decisão mais estratégicas para otimização de performance de marketing nas empresas. 


\section{Referências}

ABHISHEK, V.; FADER, P.; HOSANAGAR, K. Media exposure through the funnel: a model of multistage attribution. Disponível em SSRN:

https://ssrn.com/abstract=2158421 or http://dx.doi.org/10.2139/ssrn.2158421, ago 2012.

ABHISHEK, V.; DESPOTAKIS, S.; RAVI, R. Multi-channel attribution: The blind spot of online advertising. Disponível em SSRN: SSRN:

https://ssrn.com/abstract=2959778 or http://dx.doi.org/10.2139/ssrn.2959778, abr 2017.

ANDERL, E.; BECKER, I.; VON WANGENHEIN, F; SCHUMANN, H. Mapping the customer journey: Lessons learned from graph-based online attribution modeling. International Journal of Research in Marketing, v. 33 n. 3, p. 457-474, jan 2015.

BAUER, M. W.; GASKEL, G. Pesquisa Qualitativa com Texto Imagem e Som, um manual prático. Petrópolis, RJ: Vozes, 2017.

BERMAN, R. Beyond the Last Touch: Attribution in Online Advertising.

Disponivel em SSRN: https://ssrn.com/abstract=2384211 or

http://dx.doi.org/10.2139/ssrn.2384211, jan 2014.

BUHALIS, D., VOLCHEK, K., 2020, Bridging marketing theory and big data analytics: The taxonomy of marketing attribution. International Journal of Information Management. Disponível em:

https://doi.org/10.1016/j.ijinfomgt.2020.102253

DALESSANDRO, B.; PERLICH, C.; STITELMAN, O.; PROVOST, F. Causally motivated attribution for online advertising. Proceedings of the Sixth International Workshop on Data Mining for Online Advertising and Internet Economy, ago 2012.

ECONSULTANCY. Marketing attribution: valuing the customer journey. Londres, 2012. Disponível em:

$<$ https://www.thinkwithgoogle.com/marketing-strategies/data-and-measurement/ marketing-attribution-valuing-the-customer-journey/>. Acesso em: 25 de setembro 2021.

GIL, Antonio Carlos. Como elaborar projetos de pesquisa. 4. ed. São Paulo: Atlas, 2008

GOOGLE, Visão geral do modelo de atribuição. Disponível em: $<$ https://support.google.com/analytics/answer/1662518?hl=pt-BR>. Acesso em: 25 de setembro 2021.

KANNAN, P.; REINARTZ, W.; VERHOEF, P. The path to purchase and attribution modeling: Introduction to special section. International Journal of Research in Marketing, v. 33 n. 3, p. 449-456, jul 2016 
LEMOS, A. Optimizing multi-channel use in digital marketing campaigns. Lisboa:

NOTTORF, F. Modeling the clickstream across multiple online advertising channels using a binary logit with Bayesian mixture of normals. Electronic Commerce Research and Applications. v. 13, jan 2013

MALHOTRA, N. Pesquisa de Marketing, Foco na Decisão. Tradução opportunity Translations. 3a edição. São Paulo: Pearson, 2010

ROCHA, J. Media mix modeling: A case study on optimizing television and digital media spend for a retailer. Lisboa: Universidade Nova de Lisboa, 2019 35p. Disponível em: <http://hdl.handle.net/10362/94986>.

ZAREMBA, A. Conversion attribution: What is missed by the advertising industry? The OPEC model and its consequences for media mix modeling. Journal of Marketing and Consumer Behaviour in Emerging Markets, v. 1 n. 10, P. 4-23, nov 2020. 


\section{Apêndice 1}

1. Como o gestor mede conversões de receita/ecommerce de cada canal?

2. Como o gestor mede o impacto de resultado que o investimento em um canal de marketing trouxe?

3. Qual o modelo de atribuição que o gestor utiliza para medir as conversões dos canais na empresa?

3.1 Se a plataforma de analytics usada for o Google Analytics: Quais as vantagens que a sua empresa tem ao usar modelo de atribuição do Google Analytics? Você está satisfeito com a sua mensuração de resultados que você aplica hoje?

4. Quais são as principais dificuldades que o gestor enfrenta para fazer o planejamento de orçamento e selecionar o seu mix de mídias para os próximos meses?

5. Quais são os principais desafios que o gestor percebe como oportunidade para otimizar o investimento em marketing?

6. Que tipos de análise o gestor julga como fundamental para gerar implicações para estratégia de mix de mídias e alocação de orçamento?

7. Considerando que existe um efeito incremental entre os canais, como o gestor mede o efeito que um canal teve na conversão de um outro canal?

8. Se existisse um modelo de atribuição automático, de graça, já testado e personalizado para a jornada de consumo da sua empresa, qual(is) o(s) maior(es) benefício(s) que o gestor perceberia ao analisar os resultados utilizando esse modelo?

9. Na sua experiência, quais os principais obstáculos que você enfrentou e enfrenta para implementar uma atribuição eficaz e eficiente (que funcione, gere inteligência de performance e seja fácil de manter)? 


\section{Apêndice 2}

\begin{tabular}{|c|c|}
\hline \#1 & Coordenadora de Web Analytics em um banco digital \\
\hline 1 & $\begin{array}{l}\text { Vou usar uma resposta que ela vai aparecer em muitas perguntas tá? Então já vou } \\
\text { adiantar agora que depende muito da maturidade da empresa como a gente vai } \\
\text { medir a conversão. Porque a realidade é que os ambientes de dados dentro das } \\
\text { empresas são muito mal implementados, então você provavelmente vai medir na } \\
\text { ferramenta que for menos ruim né? Não que se tiver um pouco melhor implementar } \\
\text { então atende muito tá mas geralmente, como era eu que garantia por ser web } \\
\text { analitytics, tinha mais confiança. Por ter mais conhecimento mesmo da ferramenta } \\
\text { eu acabava utilizando o Google Analytics pra ver as conversões de receita mas eu } \\
\text { sempre comparava com as ferramentas de mídia para ver como que estava essa } \\
\text { discrepância porque a discrepância sempre vai ter. Porque as ferramentas, elas } \\
\text { medem de formas diferentes. Só que dependendo do quanto é essa discrepância } \\
\text { algo precisa ser investigado. Mas geralmente utilizava o Google Analytics para medir } \\
\text { as conversões de receita. }\end{array}$ \\
\hline 2 & $\begin{array}{l}\text { isso dependia muito do funil de marketing né? Porque cada campanha, ela vai ter } \\
\text { um objetivo então isso é uma coisa que aliás as pessoas acabam tendo um pouco } \\
\text { de dificuldade. Quando você trabalha com o marketing nem toda a campanha tem } \\
\text { objetivo de vender. Algumas campanhas têm objetivo de gerar cadastro, de gerar } \\
\text { impacto. Então depende muito. O que que eu costumava fazer para medir o impacto } \\
\text { de resultado, como geralmente diretores e superintendentes, eles entendem mais } \\
\text { número e de receita, é óbvio que você vai trazer então ROI - você vai dividir o quanto } \\
\text { foi investido e dividir pela receita. Mas se você só reportar isso, é muito pobre.Você } \\
\text { precisa entender também que impacto e como seriam essas conversões, caso... Aí } \\
\text { que entra acho que um pouco mais modelo de atribuição. Quando o anúncio foi } \\
\text { visto dentro daquela plataforma mesmo que ele não tenha sido em um modelo last } \\
\text { click. Ele pode começar a trabalhar com essas análises. Mas como eu trazia esse } \\
\text { impacto né? Eu sei o ROI é sempre calculado em cima da conversão mesmo de } \\
\text { receita mas eu sempre trazia essas outras análises junto. Então olha: este canal } \\
\text { gerou menos receita também olha quantas visitas este canal trouxe para web site; } \\
\text { olha como ele foi importante; será que a gente teria feito se a gente tivesse pulado } \\
\text { esse funil com essas visitas aqui. Eu sempre trazia uma coisa mais visual e dinheiro } \\
\text { mesmo eu deixava o ROI. O retorno do que se tornou receita mas sempre trazendo } \\
\text { essas visões. Por exemplo, No funil, eu trazia o objetivo de cada canal também. No } \\
\text { Facebook a gente tinha na verdade um objetivo de awareness. então olha quantas } \\
\text { visitas, olha como a gente aumentou brand lift, Olha como a gente aumentou o } \\
\text { nosso alcance; olha como aumentar o nosso alcance contribuiu pra gente aumentar } \\
\text { a receita nesse mês. Então eu trazia essas outras informações mais como análise do } \\
\text { que de fato métrica. Como eu falei os ambientes eles são muito pobres nesse }\end{array}$ \\
\hline
\end{tabular}




\begin{tabular}{|c|c|}
\hline & $\begin{array}{l}\text { sentido para você trazer uma coisa mais algorítmica. Acaba vindo como insight } \\
\text { mesmo separado por objetivo do funil. }\end{array}$ \\
\hline 3 & $\begin{array}{l}\text { Isso também eu vou falar de novo na maturidade da empresa. Porque quando a } \\
\text { empresa não tem muita maturidade de dados, modelo de atribuição é a coisa é a } \\
\text { última coisa que você fazer um projeto de web analytics. Porque antes você tem que } \\
\text { ver vocês se todas as métricas estão fazendo sentido; se as pessoas entendem as } \\
\text { métricas porque cada ferramenta calcula aquilo de um jeito, tem um monte de } \\
\text { cálculo sendo feito errado. Então o que eu acho Google analytics bom. Eu acho ele } \\
\text { bom porque já está pré-definido ali então pra quem não entende muito é uma } \\
\text { maneira de você mensurar de certa maneira e não está completamente errado. Ele } \\
\text { não é tão rico quanto ele poderia ser porque ele sempre vai puxar a sardinha pro } \\
\text { Google. Então mas eu acho que o modelo last click funciona muito bem para } \\
\text { empresas que não chegaram lá ainda. Para as que estão ainda descobrindo essa } \\
\text { parte de marketing digital, eu acho que ele é muito bom. Diferente do Adobe, por } \\
\text { exemplo. O Adobe é mega customizado. Então se você não tem isso documentado } \\
\text { direito, a chance de você ler alguma coisa errada é muito alta, para se fazer alguma } \\
\text { atribuição errada é muito alta. Eu acho que sim, ta? A grande vantagem é utilizar } \\
\text { empresas que não têm uma maturidade de dados de marketing digital muito grande } \\
\text { porque já tá prontinho aí pra você: simples, a chance de dar errado é muito pequena. } \\
\text { Então eu acho que essa é a grande vantagem do Google analytics. } \\
\text { Olha o pago, sim. } 360 \text { sim, mas você fazer atribuição com uma versão gratuita é } \\
\text { muito pobre de verdade. Porque em amostragem. Já não é igual né porque o GA } \\
\text { sempre vai trabalhar com estimativa porque é por cookies, então nunca vai tá igual, } \\
\text { certinho. Então quando não está integrado com o seu source, com CRM, não é tão } \\
\text { bom quanto ele poderia ser. E gratuita, pior ainda. Então assim } 360, \text { OK. } 360 \\
\text { integrado com seus sources é perfeito. Agora, gratuito não. Gratuito eu acho que } \\
\text { não vale muito a pena. Tem que usar com muito cuidado. }\end{array}$ \\
\hline 4 & $\begin{array}{l}\text { É aí eu não fazia né. Eu auxiliava bastante o pessoal de mídia para fazer o } \\
\text { planejamento. Eu acho que o que mais pesava eram as situações que a gente não } \\
\text { espera né? Então de repente uma notícia que explodiu e aí o termo foi para a lua } \\
\text { né? Então esse tipo de coisa às vezes a gente não controla e aí tem que mudar o } \\
\text { planejamento todo que foi feito por conta de alguma coisa que aconteceu. Eu acho } \\
\text { que isso era o motivo pelo qual mais me chamavam pra trazer dados pra mudar o } \\
\text { planejamento. Por exemplo, um exemplo bom quando eu trabalhava para Vivo e teve } \\
\text { um dia que explodiu lá, todo mundo estava chorando "nossa meu Deus, a Vivo tá } \\
\text { bombando". E assim era na verdade o que tinha acontecido era que queriam saber } \\
\text { se o Gugu estava vivo. A galera chegou sem querer no site sabe? Esse tipo de } \\
\text { coisas você planeja aí acontece alguma coisa e você perde completamente noção } \\
\text { do que está acontecendo. Para mim, a maior dificuldade eram esses eventos que a } \\
\text { gente não está planejando. O outro ponto é que no plano de mídia ele é feito com } \\
\text { estimativa né? Então você pega algumas métricas, depois você vai fazendo a } \\
\text { engenharia reversa né? Essas métricas tiverem mal mensuradas, com tagueamento } \\
\text { zoado, tudo vai por água abaixo. }\end{array}$ \\
\hline
\end{tabular}




\begin{tabular}{|c|c|}
\hline & $\begin{array}{l}\text { podia trabalhar ali embaixo, precisa aumentar em cima. Quando você mostra para as } \\
\text { pessoas que se você não alimentar em cima vai parar de converter em baixo então } \\
\text { realmente muito difícil de explicar isso e é por isso que é legal para construir um } \\
\text { modelo você consegue entender essa proporção. Porque também não vai ser linear } \\
\text { entendeu depende muito do modelo do negócio e se você consegue, no mundo } \\
\text { ideal, entender essa proporção para quantos por cento é preciso aumentar no alto } \\
\text { funil para conseguir manter minha conversão baixo funil. Então tem todo um estudo. } \\
\text { Não vai ser só configurar ali no Analytics como você quer que ele atribua as coisas } \\
\text { para você. Tem que entender que vai mudar muito dependendo do negócio essa } \\
\text { porcentagem. Quanto você precisa inflar em cima para chegar em baixo. } \\
\text { Outro ponto é que eu acho que é muito difícil... A média gestão, os gestores de } \\
\text { marketing, eles entendem as coisas que estão sendo faladas. Quando esse cara for } \\
\text { reportar para o gerente dele ou um superintendente de vendas, o cara não entende } \\
\text { essas métricas, ele não entende o que significam essas coisas. Então como você vai } \\
\text { passar a importância pro cara que tá super acima. A questão da linguagem também } \\
\text { que você vai passar as informações. } \\
\text { Você acha que existe algum desafio em termos organizacionais e de recrutamento } \\
\text { até para se é criar uma área mais dirigida, mais orientada por dados? } \\
\text { É um super desafio. Tem muito pouco profissional de Web Analytics. Tem muito BI. } \\
\text { Só que o Web Analytics que é uma coisa muito específica. Não é só saber mexer em } \\
\text { dados, é saber traqueamento, é saber como o Analytics funciona, é entender o } \\
\text { básico de mídias, de SEO. Então, as contratações de analytics são muito difíceis. } \\
\text { Quando eu fui cliente né a gente tentar contratar pessoas para aumentar o time é } \\
\text { muito difícil achar a gente especializada nisso. Ainda é um mercado muito novo. Por } \\
\text { isso que eu falo como é que você vai botar um modelo de atribuição se o seu } \\
\text { Analytics é gratuito e todo tagueado errado, você já tá vendo informação que não } \\
\text { faz nenhum sentido com o que você yem na sua base interna. Você não está vendo } \\
\text { visita direito. Então tem muito essa dificuldade. }\end{array}$ \\
\hline 5 & $\begin{array}{l}\text { É a minha que eu bato. Não colher uma ferramenta só. Sempre olhar mais de uma } \\
\text { ferramenta. Estar sempre testando o modelo de conversão que você atribui para } \\
\text { aquela ferramenta. Aregra de conversão dentro da ferramenta. Testar regras } \\
\text { diferentes e você comparar isso ao longo do tempo para você ver o que faz mais } \\
\text { sentido. Não assumir que porque está no Analytics é aquilo. Sempre confirmar em } \\
\text { outras ferramentas e fazer as pessoas entenderem exatamente isso. Last clique não } \\
\text { é é... Deixar claro olha a gente está olhando dessa forma mas não necessariamente } \\
\text { é a melhor forma de olhar. Estamos olhando neste momento porque é mais fácil } \\
\text { mas a ideia é que a gente evolua isso para entender melhor qual o papel de cada } \\
\text { canal. Porque primeiro você tem que explicar isso que as pessoas não entendem } \\
\text { isso. Chegar para um diretor e falar "estamos vendo no last clique", ele não vai } \\
\text { entender o que está falando. Então é só você deixar claro que você está olhando de } \\
\text { uma maneira que você vai evoluir essa maneira de olhar. Acho que esqueceu } \\
\text { primeira coisa. }\end{array}$ \\
\hline 6 & $\begin{array}{l}\text { É você verificar se em termos de ** que aquela segmentação tá fazendo sentido } \\
\text { porque por exemplo eu já trabalhei para minha empresa que eles estavam querendo }\end{array}$ \\
\hline
\end{tabular}




\begin{tabular}{|c|c|}
\hline & 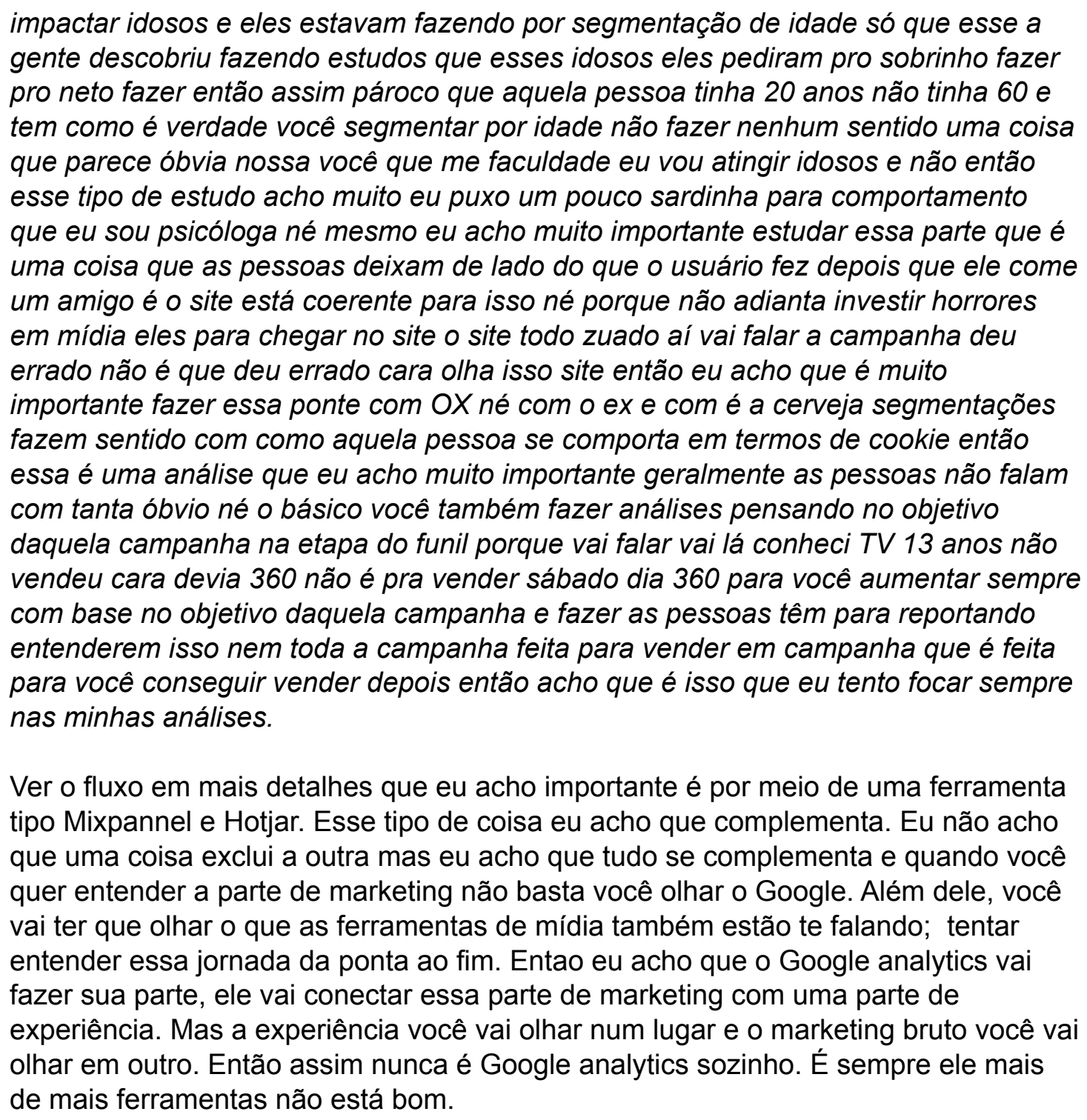 \\
\hline 7 & $\begin{array}{l}\text { Pode por isso como desafio. Eu acho que as pessoas, a área é muito } \\
\text { sobrecarregada as pessoas não têm tempo para fazer uma coisa mais legal, uma } \\
\text { coisa muito bem pensada. É tudo sempre corrido tudo sempre em cima da hora. É } \\
\text { totalmente essa cultura de marketing né? todo mundo quer tudo para ontem é muito } \\
\text { difícil de você parar implementar um modelo bem pensado. } \\
\text { É tudo para ontem né? Um negócio que tem que maturar. Você precisa construir } \\
\text { essa base devagar. Não vai dar resultado logo de começo. Não tá funcionando, não } \\
\text { tira dinheiro daqui, precisa dar tempo. Vamos fazer um modelo de atribuição } \\
\text { maravilhoso. Mas você não tem nem tagueamento direito para atribuir. Então você } \\
\text { poderiaa analisar dado errado. Então ele tem que ter calma também né? }\end{array}$ \\
\hline 8 & $\begin{array}{l}\text { Você é perfeito não é porque você não ia ter que se questionar se está olhando no } \\
\text { lugar certo né? Você já sabe qual que é o impacto que aquele canal tem e para que } \\
\text { que você tem que usar ele. Porque acho que a maior dificuldade dos projetos de } \\
\text { mídia é você entender, ao longo do tempo, para que o aquele canal vai servir para } \\
\text { aquela empresa, o quanto ele impacta e o quanto você vai dividir seu dinheiro entre }\end{array}$ \\
\hline
\end{tabular}




\begin{tabular}{|c|c|}
\hline & $\begin{array}{l}\text { os canais. Então eu acho que seria perfeito assim para essa parte de dividir o } \\
\text { dinheiro e de fazer plano de mídia. }\end{array}$ \\
\hline 9 & $\begin{array}{l}\text { A gente sempre tinha como parte do projeto implementar um modelo de atribuição e } \\
\text { a gente nunca chegava nesse ponto. Então acho que a principal dificuldade é tudo } \\
\text { que vem antes. Porque você precisa de uma maturidade para chegar lá. } \\
\text { a) Então assim você precisa ter essa comunicação com o gestor } \\
\text { comunicação com os gestores, fazer os superintendentes e diretores que } \\
\text { não têm conhecimento técnico entenderem porque isso é importante. } \\
\text { b) Você tem toda a coleta e precisa garantir que os dados estão corretos, } \\
\text { implementar primeiro as coisas, } \\
\text { c) ter uma base para trabalhar } \\
\text { para daí você pensar até dados históricos para você começar a pensar num modelo } \\
\text { de atribuição. Tem que olhar o seu histórico e entender percentualmente qual foi o } \\
\text { impacto de cada mídia, de cada tipo de mídia naquela conversão. Então eu acho } \\
\text { que precisa de tempo e todo esse processo é uma coisa que demora pra ser feito. } \\
\text { Eu só vi isso ser feito em um case sinceramente todos os meus anos. Eu só vi ser } \\
\text { feito no magazine luiza e deu no que deu né: eles são super ótimos em questão de } \\
\text { digital. Então assim tem uns casos de sucessos mas para isso acontecer demora. }\end{array}$ \\
\hline
\end{tabular}

\begin{tabular}{|l|l|}
\hline \#2 & Gerente de Mídias Pagas de empresa de serviços de investimentos \\
\hline 1 & $\begin{array}{l}\text { A gente tem consolidado dentro de caso algumas formas de mdir a conversão de } \\
\text { receita e isso sempre vai depender em que nível ou qual o objetivo da discussão } \\
\text { que estamos tendo de desempenho. Então, a primeira forma seria medir dentro da } \\
\text { própria plataforma de anúncio. Faz un anunico, gera uma sessao, se essa sessao } \\
\text { gera uma conversao. Essa conversao é enviada para a plataforma. Esse é o } \\
\text { primeiro contato com a transação de receita. Sinal que a plataforma recebe do } \\
\text { nosso site, da nossa pagina de venda. A forma mais distante da realidade de } \\
\text { negócios da Suno. Considerando as regras de negócios, existem regras que } \\
\text { definem uma transação. Se a transação foi paga ou foi devolvida. Mas na outra } \\
\text { ponta, tem a realidade da plataforma. A leitura de sinais online que faz a integração } \\
\text { entre o ecommerce e a plataforma. A segunda forma seria ver o sinal de conversão } \\
\text { gerado dentro do Google Analytics. Ela é bem semelhante com a primeira, porque a }\end{array}$ \\
\hline
\end{tabular}




\begin{tabular}{|c|c|}
\hline & $\begin{array}{l}\text { gente ainda está falando de uma visão de web analytics, desempenho de } \\
\text { navegação e não desempenho financeiro. O que eu vejo de diferente: como são } \\
\text { plataformas diferentes, elas têm configurações diferentes de atribuição. Um exemplo } \\
\text { é a questão de atribuição de dados. São duas formas de medir o desempenho de } \\
\text { conversão Web Analytics, mas como são plataformas diferentes podem gerar } \\
\text { análises e insights diferentes. A terceira seria a mais próxima da realidade de } \\
\text { negócio da empresa. Pra ver o número de fato que cai na conta da empresa que } \\
\text { importa pra saúde de negócio. Talvez pra estratégia de mídias, não sei se é melhor } \\
\text { visão. Pro negócio, a forma mais recomendada é considerando as regras de } \\
\text { negócio da Suno. Entra alguns complicadores. A regra é única para cada empresa, } \\
\text { não existe um template. Cada negócio define suas regras de negócios. A conversão } \\
\text { deve ser uma métrica relativa, uma proporção. Conversão em receita talvez é até } \\
\text { algo estranho de entender. O que converte em receita, uma sessão? Não são duas } \\
\text { coisas que são medidas na mesma métrica. Então tem toda essa complicação se a } \\
\text { gente considerar a receita de fato entendida pelo negócio e a gente precisa ter outra } \\
\text { métrica pra poder fazer essa proporção. Se for medir conversor de ecommerce, } \\
\text { numero de transacoes pelo numeor de sessoes ou cliques e assim por diante. Existe } \\
\text { uma parte nessa questao de medir conversoes que é muito importante na questao } \\
\text { de definicao. O que significa para a empresa? O que foi definido e o que as pessoas } \\
\text { entendem na comunicação interna? }\end{array}$ \\
\hline 2 & $\begin{array}{l}\text { Essa é uma questão de opção. Retorno real sobre investimento real. Receita que a } \\
\text { Suno recebeu dividido pelo valor que a gente gastou. Isso porque quando a gente } \\
\text { fala de ROI, a gente tá falando da performance da plataforma. Se a gente medir } \\
\text { performance de uma maneira errada, a gente é induzido ao erro. }\end{array}$ \\
\hline 3 & $\begin{array}{l}\text { A gente usa as configurações padrões do GA. Sinceramente, não tenho } 100 \% \text { de } \\
\text { firmeza, mas o modelo de atribuição é last-click com uma janela de atribuição de } \\
180 \text { dias. O modelo é um pouco além do last-click. Se um canal que utiliza utms } \\
\text { gera uma sessao, o GA associa o user id com esse parâmetro de utm. Se dentro de } \\
\text { uma janela de } 6 \text { meses e sendo a próxima navegação uma sessão direta (sem } \\
\text { parametros de utms) ele vai associar essa sessao aos parametros de utm que ele } \\
\text { conhece. }\end{array}$ \\
\hline 4 & $\begin{array}{l}\text { Não, a gente, eu não to satisfeito. Porque a questao da mensuração como fazemos } \\
\text { no GA acaba impactando a nossa mensuracao da transacao real dos canais. A } \\
\text { gente utiliza esse modelo do GA de atribuicao das transacoes pra associar os } \\
\text { canais as transacoes reais recebidas pela Suno. Entao, de certa forma, e a solucao } \\
\text { que temos hoje, mas nao e o ideal. Pro GA, acho que a forma como e a mensurada } \\
\text { ela distoa do modelo de negocio. O modelo de negocio da Suno analisa o canal que } \\
\text { gerou a sessao e vendeu, e nao se ele foi o ultimo conhecido. Entao, existe esse } \\
\text { desalinhamento. Pensando em GA, por si so, eu to semi-satisfeito. Nao fico } 100 \% \\
\text { com a janela de atribuicao tao grande que a gente tem. O padrao de } 180 \text { dias e } \\
\text { bastante. As vezes a gente vai perceber que a campanha ate parou e gerou uma } \\
\text { conversao. Se for pra usar um modelo last click, eu prefiriria um last click puro. } \\
\text { Resumindo, eu to semi-satisfeito, porque a janela de } 180 \text { dias é muito longa. Aqui a } \\
\text { gente tá falando de ser justo e ser claro. O dado é o mais puro, consistente e limpo } \\
\text { possível. }\end{array}$ \\
\hline 5 & $\begin{array}{l}\text { O gestor precisa garantir que vai atender à expectativa da diretoria e CEO. Tenho } \\
\text { que garantir isso com as ferramentas que temos disponíveis. As ferramentas que }\end{array}$ \\
\hline
\end{tabular}




\begin{tabular}{|c|c|}
\hline & $\begin{array}{l}\text { temos não são } 100 \% \text { das ferramentas do mercado, sempre podemos contar mais } \\
\text { opções, ex: outra plataforma de anúncio. Outra dificuldade são as constantes } \\
\text { mudanças que tem nesse ambiente de anúncios }\end{array}$ \\
\hline 6 & $\begin{array}{l}\text { São muitos. Os principais que me vem a cabeça. Na questao de otimizar } \\
\text { investimento, precisamos superar ter uma estratégia robusta rodando. A partir desse } \\
\text { momento, otimizar investimento destrava em várias partes pode travar se não tiver a } \\
\text { estratégia. Acho que esse é o primeiro ponto. Não é desafio, mas um pré-requisito } \\
\text { na questão de otimizar investimento. O primeiro desafio: a partir de uma estrategia } \\
\text { robusta, nem todo o investimento retorna ROAS. Entao, a gente ta falando de uma } \\
\text { atuacao multivariada, com diversos objetivos de campanha, e o grande desafio } \\
\text { acaba sendo: como justificar e dar a transparencia o resultado de acoes que nao } \\
\text { trazem resultado de imediato. Exemplo é uma campanha pra gerara trafego ou de } \\
\text { visualizacao de video. Ela nao traz retorno direto pra empresa. Se olharmos com } \\
\text { esses olhos, isso gera uma insustentabilidade para a estrategia. O desafio é } \\
\text { conseguir associar as variadas estrategias com as metricas que sao devidas para } \\
\text { aquele tipo de resultado. Se a gente ta falando de uma campanha de trafego e esse } \\
\text { é o objetivo, temos que ver isso sob a perpectiva de custo por clique. Na perspectiva } \\
\text { receita last click, a conclusao e que a gente nao deveria ter essa campanha. Outro } \\
\text { desafio que é muito associado a esse é de fato a gente conseguir depois unir todos } \\
\text { esses custos que a gente tem ao longo da jornada do usuario. A gente basicamente } \\
\text { pode pagar varias vezes pelo mesmo usuario e isso no final das contas vai compor } \\
\text { o custo que a gente teve ao longo da vida dele. A dificuldade conseguir atribuir o } \\
\text { custo de cada estrategia, porque caminhando nesse sentido a gente começa a ter a } \\
\text { possibilidade de justificar as vezes acoes que nao fazem sentido quando a gente } \\
\text { tem olhar pontual e nao um olhar amplo }\end{array}$ \\
\hline 7 & $\begin{array}{l}\text { Eu acho que é mais na primeira versão. Eu vejo isso como uma interacao } \\
\text { multifuncional entre areas. Dentro de todos cadeia do marketing digital, a parte de } \\
\text { anuncio pago é um das variedades: temos midias organicas, email marketing, } \\
\text { conteudos organicos etc. Acho que muito sustentado pelo comportamento de } \\
\text { compra atual dos usuarios. Cada vez mais o comportamento é multitouch. A pessoa } \\
\text { nao simplesmente pensa que vai comprar uma bolsa: vai pro shopping e compra a } \\
\text { bolsa. Considerando que esse comportamento de compra do usuario é nesse } \\
\text { formato, os outros canais que participam da estrategia de marketing, eles tem um } \\
\text { papel fundamental de sustentar a estrategia. Isso é desde o inicio. Se pensar numa } \\
\text { das atividades principais que temos: geracao de leads. O que seriamos de midias } \\
\text { pagas se captássemos leads e o time de email não enviasse email. }\end{array}$ \\
\hline 8 & $\begin{array}{l}\text { Isso daria uma visao claro da contribuicao de cada um dos canais na etapa na } \\
\text { evolucao da jornada do usuario. O grande beneficio nao e ter a visao claro, mas o } \\
\text { que a visao te permite depois. A etapa do usario é uma evolucao que sempre tem } \\
\text { desistencia. Podemos ver isso como funil e de que para todas etapas existe uma } \\
\text { taxa de conversao. Mapeado isso e conseguindo atribuir a participacao de cada um } \\
\text { dos canais, teriamos uma visao clara de quais sao os gargalhos e onde sao os } \\
\text { pontos de atencao. Qual a etapa onde os usuarios desistem. A partir da visibilidade, } \\
\text { a gente vai ter clareza e conseguir identificar quais sao os principais ofensores. Em } \\
\text { cima deles que precisamos trabalhar. }\end{array}$ \\
\hline 9 & $\begin{array}{l}\text { A primeira é a questao da prioridade. Esse assunto é super relevante, mas diante } \\
\text { dos outros, na fase em que a empresa esteja, talvez tenha menos prioridade. }\end{array}$ \\
\hline
\end{tabular}




\begin{tabular}{|l|l|}
\hline Quando já tivermos superado obstáculos básicos, no nível avançado da discussão, \\
essa pauta sera mais interessante. Nao sendo prioridade, é uma discussao \\
superficial porque tambem nao é uma prioridade para a gestao da empresa. Nao \\
adianta o canal querer defender esse tipo de premissa se isso nao e o que é \\
necessario para a empresa no momento. E ai os outros decorrrem das dificuldades \\
tecnicas de implementacao e associacao. A partir de um momento que a gente vai \\
fazer, o que a gente vai fazer, quais sao as regras. Definidas as regras e premissas, \\
como a gente faz as regras funcionarem. Nao e prioridade. Existe a questao de \\
estarmos falando de atribuicao automatica a partir de umas regras. Existe a parte de \\
definicao de regras que nao e algo simples. Quanto maior for a complexidade da \\
regra de negocio, maior e o orpblema de implementar. Por isso, a maioria das \\
empresas nao tem prioridade sobre esse assunto e acaba utilizando o padrão do \\
mercado.
\end{tabular}

\begin{tabular}{|l|l|}
\hline \#3 & $\begin{array}{l}\text { Coordenadora de Web Analytics em uma empresa internacional de beleza e } \\
\text { cosméticos }\end{array}$ \\
\hline 1 & $\begin{array}{l}\text { Depenedendo do objetivo da campanha o ROAS vai ser negativo e tudo bem. Eu uso } \\
\text { o GA mas nem todas as ferramentas estão lá. O Google Ads por ser do Google a } \\
\text { gente pega tudo de lá mesmo. Mas se for outras plataformas como Facebook ou } \\
\text { Criteo, tem que pegar os valores de custo lá. Sempre falo para todos que trabalham } \\
\text { com Analytics e medir o desempenho usando uma única plataforma de Analytics. } \\
\text { Investimento obviamente nao vai ter todos os canais, mas o ideal é ver a receita pela } \\
\text { mesma ótica }\end{array}$ \\
\hline 2 & $\begin{array}{l}\text { O email geralmente na Metricas, a gente trabalhava com diversos clientes. O que a } \\
\text { gente pedia era o investimento pra plataforma de email. A gente media atraves disso. } \\
\text { As redes sociais geralmente é pra awareness. Entao nem via questao de investimento } \\
\text { ou receita. SEO fazia muita analise do que podia melhorar no site. Pra ver o quanto } \\
\text { tava rankeando no Google orgânico. }\end{array}$ \\
\hline 3 & $\begin{array}{l}\text { Todas as empresas que trabalhei a gnte usava GA, que é ultimo clique nao direito por } \\
\text { ser o modelo padrao. Mas a gente sabe que existem outros modelos. Inclusive o } \\
\text { Google lancou o Google Attribution para poder comparar com outros modelos. O que } \\
\text { vejo muito no mercado é ver no GA com ultimo clique nao direio. Muita gente pensa } \\
\text { que e last click, mas na verdade e last click nao direto. Quando a pessoa entra direto, } \\
\text { ele considera o penultimo. Pela maioria dos navegadores já ficarem cookados ali no }\end{array}$ \\
\hline
\end{tabular}




\begin{tabular}{|c|c|}
\hline & $\begin{array}{l}\text { site. } \\
\text { "E o Google Attribution?" Muito pouco. Eu mesma usava pouco. Porque e uma } \\
\text { ferramenta nova, muita gente nao entende como manusear. Muita gente nao fala } \\
\text { muito sobre atribuicao. A principal vantagem é ver todos os canais por um mesmo } \\
\text { modelo. Tem uma nocao melhor do que está dando resultado ou não. }\end{array}$ \\
\hline 4 & $\begin{array}{l}\text { Eu nao fzia isso no dia a dia. Mas o que via la e agora na Avon. Separar o que vc } \\
\text { quer que traga trafego para o site, como reconhecimento de marca, e o que vc quer } \\
\text { que traga performance. A Avon investiu muito no Big Brother e trouxe um grande } \\
\text { resultado de trafego. E hoje perto da Black Friday o volume diminuiu muito. A marca } \\
\text { que ja ta consolidada. O Spoleto quase nao faz parte de reconhecimento de marca. } \\
\text { Mas tem que ter um mix. Pessoal que ta no alto escalao de marca nao entende muito. } \\
\text { As vezes nem sempre e assim. Vc traz o publico para o site e converte depois. } \\
\text { "E sobre a diferença de fazer o planejamento de midia para empresas grandes e } \\
\text { para empresas pequenas?" Acho que dependendo do tamanho da empresa e do } \\
\text { que ela vende, algo que tem uma saida muito alta é diferente de vender produto de } \\
\text { beleza como a Avon. Marca que tao consolidadas é diferente de marcas que estão } \\
\text { fazendo rebranding. }\end{array}$ \\
\hline 5 & $\begin{array}{l}\text { Uma dificuldade que percebo é que o site é dividido por cartegoria: toilet, maquiagem, } \\
\text { perfume, face. Cada categoria tem uma equipe. Cada equipe quer o maior } \\
\text { investimento porque eles têm uma meta pra vender aqui. Algo que na Americas, nao } \\
\text { tinha essa nocao. Pra mim o site tem que vender, passar a meta. E nao pensar que } \\
\text { tem que vender mais um certo produto a mais do que outro. Principalmente nas } \\
\text { campanhas de Google Shopping, de priorizar o produto que vai vender. E } \\
\text { dependendo do produto. Maquiagem cresceu por causa do Big Brother. Nao precisa } \\
\text { investir tanto em reconhecimento de marca, porque ja cresceu muito. Toilet por outro } \\
\text { lado, nao é muito conhecido. Isso acaba dificultando pra equipe de mídia. } \\
\text { Valeu muito a pena o investimento no Big Brother. Cresceu tanto a receita quanto o } \\
\text { trafego. O que nao esta dando certo sao as divulgacoes da Juliette. O que vendeu } \\
\text { mesmo foi durante o programa. } \\
\text { Algumas campanhas sao pra atrair revendedoras. Como medir quanto que investi pra } \\
\text { trazer a revendedora e quanto que ela trouxe de vendas no final. }\end{array}$ \\
\hline 7 & $\begin{array}{l}\text { Tem no GA um relatorio chamado de Caminhos de conversao mais comuns. Isso e } \\
\text { legal pra medir as campanhas de trafego. Normalmente eu colocava } 30 \text { dias. Mas } \\
\text { pode colocar } 90 \text { dias pra ser um tempo mais razoavel. Ela acaba sim tendo um mérito } \\
\text { pra conversao, apesar de nao ter sido o canal que trouxe a conversao final } \\
\text { Pelo GA, a gente via qual era a ultima nao direta. Mas tem essa dificuldade no } \\
\text { mercado. Por isso o Google lancou o Google Attribution na sua conquista da } \\
\text { conversao. Mas o que eu vejo a galera de marketing e ecommerce nao ta muito } \\
\text { preocupado com isso. As vezes vc faz uma divulgacao na TV e depois a pessoa vai e } \\
\text { converte num canal organico. Entao ele teve seu merito, sim. O que eu vejo é que as } \\
\text { pessoas nao se preocupam muito com isso. } \\
\text { O que acontece muito no Brasil é que o brasileiro que trabalha no marketing e } \\
\text { ecommerce, ele é generalista. Ele faz de tudo um pouco. Alguns países como EUA e } \\
\text { na Europa, a cultura de analytics mais enraizada, eles sao mais especialistas. Uma é } \\
\text { focada em SEO, outra Facebook Ads, outra Google Ads etc. Será que em outros } \\
\text { países eles dão mais atenção pra atribuição do que aqui? }\end{array}$ \\
\hline
\end{tabular}




\begin{tabular}{|c|c|}
\hline & $\begin{array}{l}\text { "A estrutura organizacional da empresa influencia?" } \\
\text { Eu acho que sim, mas o que eu acho que o pessoal de analytics deve ter cuidado é } \\
\text { como mostrar a importância disso. O que vi na Metricas e na Avon. Trabalhar com } \\
\text { Analytics é ver numero o dia inteiro. Quando vc fala com um gerente que tá vendo } \\
\text { uma apresetnaçao, acaba que a pessoa nao ve muito valor naquilo. A maneira de } \\
\text { mostrar a importancia para tambem pegar atencao do publico e ele ver que aquilo que } \\
\text { faz sentido. Falta um pouco para os profissionais. Tomar um cuidado na hora da } \\
\text { apresentação, treinar, explicar por que mensurar o modelo de atribuição e ver qual o } \\
\text { canal que trouxe a conversão e que cada um tem a sua importância. }\end{array}$ \\
\hline 8 & $\begin{array}{l}\text { Acho que o maior beneficio seria ver se aquele tipo de campanha tá trazendo nao so } \\
\text { conversao direta mas tambem indiretamente. E se fosse personalizado, ia ser melhor } \\
\text { ainda. Seria de acordo com aquele negocio. As vezes depende do negocio. As vezes } \\
\text { o modelo de atribuicao pode atender um tipo de negocio e nao atender outro. Se } \\
\text { fosse personalizado, seria perfeito. }\end{array}$ \\
\hline 9 & $\begin{array}{l}\text { Acho que falta de conhecimento de todo mundo sobre isso. As empresas tinham que } \\
\text { ter um treinamento geral principalmente para as áreas de marketing e ecommerce o } \\
\text { que é um modelo de atribuição. As empresas pensarem só na venda direta. As vezes } \\
\text { focar num canal que traz trafego, pode ser positivo para venda tambem. } \\
\text { Principalmente, levar o conhecimento. Muita gente não entende a importância }\end{array}$ \\
\hline
\end{tabular}

\begin{tabular}{|l|l|}
\hline$\# 4$ & Diretor Geral de empresa de serviços de investimentos \\
\hline 1 & $\begin{array}{l}\text { É o formato de medir primário que a gente usa. Como que a gente garante isso né? } \\
\text { A gente leva as sources dele - as fontes e os meios e os canais... tudo que está no } \\
\text { Analytics junto com a transação e o produto para o nosso banco de dados. Então o } \\
\text { nosso banco de dados usa nosso produto com as informações que vêm do Analytics. } \\
\text { Então a gente tem 100\% preciso no banco de dados mas, no dia a dia, assim o } \\
\text { Analytics ajuda a dar um bom cheiro do que do que está acontecendo com o nosso } \\
\text { desempenho. Então é dessa forma e é last-click. }\end{array}$ \\
\hline 2 & $\begin{array}{l}\text { A gente só usa o banco de dados porque eventualmente o Analytics pode disparar } \\
\text { tags que não necessariamente correspondem a uma venda completa né? Então } \\
\text { esses erros podem existir, então não tem como ter isso? Com a base, todas as } \\
\text { conversões dos links vão para o banco de dados e aí lá ele cruza aquele ID com o ID } \\
\text { da venda real. E aí bate imediatamente sobre alguns que não acabaram sendo } \\
\text { pagos. } \\
\text { Como é que a gente mede o impacto de cada canal? } \\
\text { No nosso modelo todos os canais são importantes. A gente dificilmente desprioriza } \\
\text { algum completamente porque ele não está trazendo receita last-clique etc. Então, } \\
\text { sabendo que todos os canais tem a sua importância, a gente consegue } \\
\text { eventualmente, mesmo sabendo que last-clique talvez não seja a melhor conversão } \\
\text { ou a melhor forma de medir é isso, a gente acaba mantendo os investimentos dessa } \\
\text { forma. Então a gente não mede exatamente o impacto de cada canal no funil. A } \\
\text { gente sabe que todos os nossos canais são super positivos, isto é, tem ROAS super }\end{array}$ \\
\hline
\end{tabular}




\begin{tabular}{|c|c|}
\hline & $\begin{array}{l}\text { positivo. Todos eles têm impacto positivo, então a gente acaba vendo de maneira } \\
\text { geral last-clique. } \\
\text { Não chegou a aprofundar assim sabe? Se eu tô falando de atribuição, como que } \\
\text { cada canal impacta no funil... a gente não vai a isso. eu acho que a gente deve em } \\
\text { algum momento em breve mas hoje a gente acaba olhando é de outras em outros } \\
\text { formatos. } \\
\text { Como a gente olha isso no banco de dados nesse caso os dados não acabam } \\
\text { batendo porque a gente considera o direto e esse direto para a gente é entre aspas } \\
\text { orgânico. E não orgânico Google, mas é um orgânico que a pessoa digitou o seu site } \\
\text { ali. O direto então é uma venda orgânica né? Então a gente não precisou gastar com } \\
\text { mídia para isso diretamente, eu não preciso de redes sociais diretamente. Então a } \\
\text { gente acaba vendo dessa forma que a gente coloca isso como um direto/orgânico. }\end{array}$ \\
\hline 3 & $\begin{array}{l}\text { Eu acho que a gente desenvolveu um modelo que é bem diferente do que do que o } \\
\text { mercado faz. Então eu fico bastante satisfeito com o ver last-clique nos levou a } \\
\text { desenvolver. Então, por exemplo, uma coisa que a gente avalia aqui e que talvez se } \\
\text { a gente usasse um modelo de atribuição a gente não tivesse conseguido } \\
\text { desenvolver, ver o ROAS por por campanha e por safra. Por exemplo, em mídia } \\
\text { paga - você conhece bem - a gente vai olhar a safra e vai olhar a campanha de cada } \\
\text { um dos leads que a gente gerou e ver eventualmente em quanto tempo esse lead vai } \\
\text { converter para que para essa safra tenha um ROAS positivo. Eventualmente se a } \\
\text { gente usasse um modelo de atribuição como nossa fonte principal, isso seria menos } \\
\text { importante só que a gente estaria deixando de avaliar safra por safra entendeu? } \\
\text { Então eventualmente eu poderia estar trazendo safras não tão boas mas o } \\
\text { investimento se manteria OK... eu continuaria tendo um ROAS ok por atribuição. E aí } \\
\text { eu ia sentir esse impacto no médio prazo entendeu? Então eu acho que o fato da } \\
\text { gente ver safra por safra no last-click, tipo a pessoa vem pela safra depois comprou. } \\
\text { Isso ajuda bastante a gente. Eu tô falando nesse caso da atribuição do lead } \\
\text { obviamente. Então eu acho que, sim, eu estou satisfeito com o que a gente } \\
\text { desenvolveu até aqui. O próximo passo que a gente precisa dar... aí sim alguns tipos } \\
\text { de investimentos, principalmente em conteúdo para a formação das pessoas, } \\
\text { precisam ser medidos por atribuição. Então quando eu crio funil completo em um } \\
\text { canal por exemplo... quando eu crio um funil completo multicanal pré a pessoa ser } \\
\text { nosso lead, nosso é contato nosso prospect. Isso não tem como eu medir sem ser } \\
\text { por atribuição. Então isso é algo que a gente tem que evoluir. }\end{array}$ \\
\hline 4 & $\begin{array}{l}\text { Orçamento e selecionar um mix de mídias que será usado nos próximos meses e a } \\
\text { ideia aqui é um pouco mais misturar ali com combinar com a aquela ideia ali de como } \\
\text { é que se mede o? Impacto retorno sobre investimento em cada canal então como é } \\
\text { que a gente faz né aí essa lógica a gente investe... basicamente quando a gente tá } \\
\text { falando de venda direta e eu vou falar bem especificamente do que a gente de fato } \\
\text { investe que é a mídia paga, que a gente investe na frente digamos assim - porque o } \\
\text { restante não é assim. É óbvio que eu vou esperar ROI do número de pessoas de } \\
\text { redes sociais e etc. Mas são mídias muito orgânicas e que a gente tem um retorno } \\
\text { muito bom. } \\
\text { Mas falando especificamente de mídia paga. Tem } 2 \text { formas que a gente traz a } \\
\text { pessoa para funil. Então compra o lead ou a gente faz venda. Venda é ROAS last } \\
\text { click na veia. Você colocou uma campanha, aquela campanha vendeu ou não... } \\
\text { ROAS que você tem ali. E aí uma campanha de venda o teu o teu orçamento é }\end{array}$ \\
\hline
\end{tabular}


infinito né. Por exemplo, eu tô com uma campanha com ROAS de 2 ou 3 aqui de venda, eu vou investir. É óbvio que eu tenho que entender os outros custos envolvidos, como imposto, custo da empresa e tal. Então tem que saber mais ou menos qual o CAC. Mas é uma campanha que está performando 3, 4 ou 5, provavelmente o meu budget para ela é infinito até ela diminuir essa performance? Quando eu tô falando de investimento em leads, que é o forte, o nosso principal investimento... o que a gente faz é justamente isso que eu te falei a gente mede como é que está a conversão daquela safra no curto prazo. Então por exemplo é eu trouxe uma safra de uma campanha $\mathrm{x}$ que a gente fez pensando em um público y... eu preciso entender com o passar do tempo quanto essa campanha essa campanha tá convertendo. Então é óbvio que demora um tempo pra pra ter esse entendimento mas eu sei que se eu tenho um ROAS de $10 \%$ na primeira semana, $30 \%$ nos primeiros 30 dias por exemplo e isso corresponde a uma conversão de $1 \%$ das pessoas que que entraram naquela campanha, daqueles leads que vieram daquela campanha em 30 dias, provavelmente com os dados que a gente eventualmente estuda, a gente vai saber que essa é uma campanha é que vai me dar um ROAS em 180 dias ou 150 dias. E aí cabe a gente, dentro do nosso modelo de negócio, entender qual é a nossa curva de ROAS positiva para que isso encaixe no nosso caixa. Então a gente está disposto a investir em leads que tenham uma boa conversão, mas tem ROAS positivo só daqui a 360 dias. A minha decisão de investimento depende muito mais de entender a curva desse lead de conversão dele do que de fato de uma limitação de orçamento, entendeu?

Óbvio que a gente faz uma meta de quanto que a gente espera disso. Mas a meta depende muito mais se a gente encontra campanhas que no dia a dia a gente vê que tem potencial de ser muito boa. A gente pode mudar essa locação facilmente para escalar. Na prática é difícil isso acontecer. Então a nossa briga é sempre trazer mais leads com a mesma qualidade e a gente acaba nem atingindo o orçamento total que a gente coloca. Bem na prática né. A nossa a nossa decisão está muito mais relacionada com essa curva de conversão do que de fato ao limite. A gente define um valor que a gente imagina que seja suficiente fazendo uma média pelo número de leads que a gente precisa trazer e aí vai trabalhando com isso ao longo do mês.

Vale a pena investir essa pessoa depois que ela virou um lead?

Cada vez mais vale. A gente historicamente não fazia isso. Então para a gente o que importa é o lead novo né? Todas as nossas métricas são em relação ao lead de novo. O que a gente vai adicionar ao longo dos próximos próximos meses é, dentro do nosso custo de aquisição, contar quantas vezes ele precisou voltar, quanto a gente precisou impactá-lo de novo e aí dentro disso também a gente tem que avaliar o ROAS dele. Então lembra que eu falei do ROAS por campanha, eu vou atribuir... eu posso escolher a forma de atribuir, que já é um tipo de atribuição mas é uma atribuição que a gente está criando da nossa cabeça. Mas aqui a gente já vai conseguir atribuir de certa forma se eu investi em uma pessoa em uma campanha $x$ em março e eu continuei investindo para ela ter outros impactos ao longo do ano por exemplo. Eu posso atribuir ao ROAS dela com todos esses impactos que ela teve isso é algo que a gente não faz hoje. A gente olha estritamente aquele impacto do investimento na primeira vez que ela vem e deixa de investir nela ao longo do tempo, a não ser em campanhas específicas né tipo Black Friday. Mas o que a gente vai fazer vai ser começar a somar esse custo e a gente vai entender o ROAS de uma forma diferente e vai ficar muito mais tranquilo em continuar investindo nesses leads. 


\begin{tabular}{|c|c|}
\hline 5 & $\begin{array}{l}\text { O principal desafio eu não acho que está - eu eu tô falando muito da nossa } \\
\text { perspectiva aqui da empresa né, imagino que isso muda para empresas de portes e } \\
\text { tamanhos diferentes. Para mim o principal desafio não está em budget pensando em } \\
\text { investimento. O meu principal desafio está em operação. Então como eu consigo } \\
\text { criar um time que seja especializado nas plataformas, desde de pensar em peças } \\
\text { para as plataformas, testes etc, a ponto de otimizar o máximo possível essas } \\
\text { campanhas que eu falei. Porque, como eu eu falei, o meu problema não é } \\
\text { orçamento. Se você tiver ROAS positivo nas campanhas de vendas, tipo sei lá acima } \\
\text { de de } 100,200 \% \text { que é super possível. Se a gente tiver leads que convertam dentro } \\
\text { de um prazo x com ROAS com de } 200,180 \text { dias que é o nosso caso. Tá o meu } \\
\text { problema é como que eu escalo dentro desse público e eu acho que esse é um } \\
\text { problema quase } 100 \% \text { de operação em plataforma. Tipo é testar peças diferentes o } \\
\text { tempo todo e estilo de campanha, modelo de campanha modelo que a gente tinha } \\
\text { gente utiliza as plataformas e tal. Eu acho que é muito mais aí essa otimização. Isso } \\
\text { otimiza o investimento porque eu deixo de pagar } 20 \text { em um lead pra pagar } 15 \text { por } \\
\text { exemplo ou eu pago } 20 \text { no lead que converte antes. É muito mais aí do que } \\
\text { investimento memso. É muito mais operação o meu desafio. }\end{array}$ \\
\hline 6 & $\begin{array}{l}\text { É isso que eu te falei vai parecer repetitivo mas acaba me ajudando no longo prazo. } \\
\text { Porque, por exemplo, se eu sei que a curva de uma de uma campanha ou de uma } \\
\text { safra que converte nos primeiros } 30 \text { dias sei lá tem um retorno de } 20 \% \text { ou } 30 \% \text { do } \\
\text { investido, eu sei que muito provavelmente, considerando algumas coisas que } \\
\text { obviamente afetam essa curva pois existem fatores exógeno e também tem alguns } \\
\text { fatores dentro desse público que podem mudar isso. Mas normalmente vai me dar } \\
\text { um retorno de } 300 \% \text { ou } 500 \% \text { em é } 360 \text { dias... Não sei estou com números } \\
\text { aleatórios aqui mas é porque isso me ajuda para de falar um prazo. Analisando bem } \\
\text { a safra do momento daquela safra me ajuda planejar a longo prazo porque eu vou } \\
\text { saber melhor qual vai ser a minha conversão quando vem meu retorno obviamente. } \\
\text { Dificilmente a gente direciona budget para um mix de mídias sem esse dado. } \\
\text { Eu sempre direciono com base no que a gente tem hoje. A gente usa muito Google e } \\
\text { Facebook né? Eu tenho essas } 2 \text { plataformas. Eu gostaria de escalar. Então o ideal é } \\
\text { que a gente invista o dobro ou triplo do que a gente investe hoje em cada plataforma. } \\
\text { O meu desafio é muito mais conseguir trazer a qualidade que eu quero do que } \\
\text { investir entendeu? Então o meu planejamento é muito mais relacionado a isso. É } \\
\text { essa otimização do que a otimização do investimento em si. Eu quero novas } \\
\text { plataformas de programática, vou testar aí pensando em canais de uma forma mais } \\
\text { aberta, vou testar é sei lá branded content, vou avaliar como isso traz retorno. Dá pra } \\
\text { fazer várias dessas coisas né? Só que a gente hoje, no nosso caso, a gente ainda é } \\
\text { muito focado no Google Ads e Facebook Ads, tem uma outra coisa além disso. E aí o } \\
\text { planejamento de mídia então é como eu vou mudar isso e o que eu mais quero } \\
\text { testar. E aí é verba de teste. Preciso testar X aí eventualmente a gente escala ou não } \\
\text { a depender do resultado. }\end{array}$ \\
\hline 7 & $\begin{array}{l}\text { No nosso modelo é impossível. E aí o que a gente faz é confiar que ele existe. E } \\
\text { obviamente ele existe. No modelo que a gente desenhou não é possível medir. Eu } \\
\text { gostaria de evoluir para tanto do ponto de vista que eu te falei antes né... A gente }\end{array}$ \\
\hline
\end{tabular}




\begin{tabular}{|c|c|}
\hline & 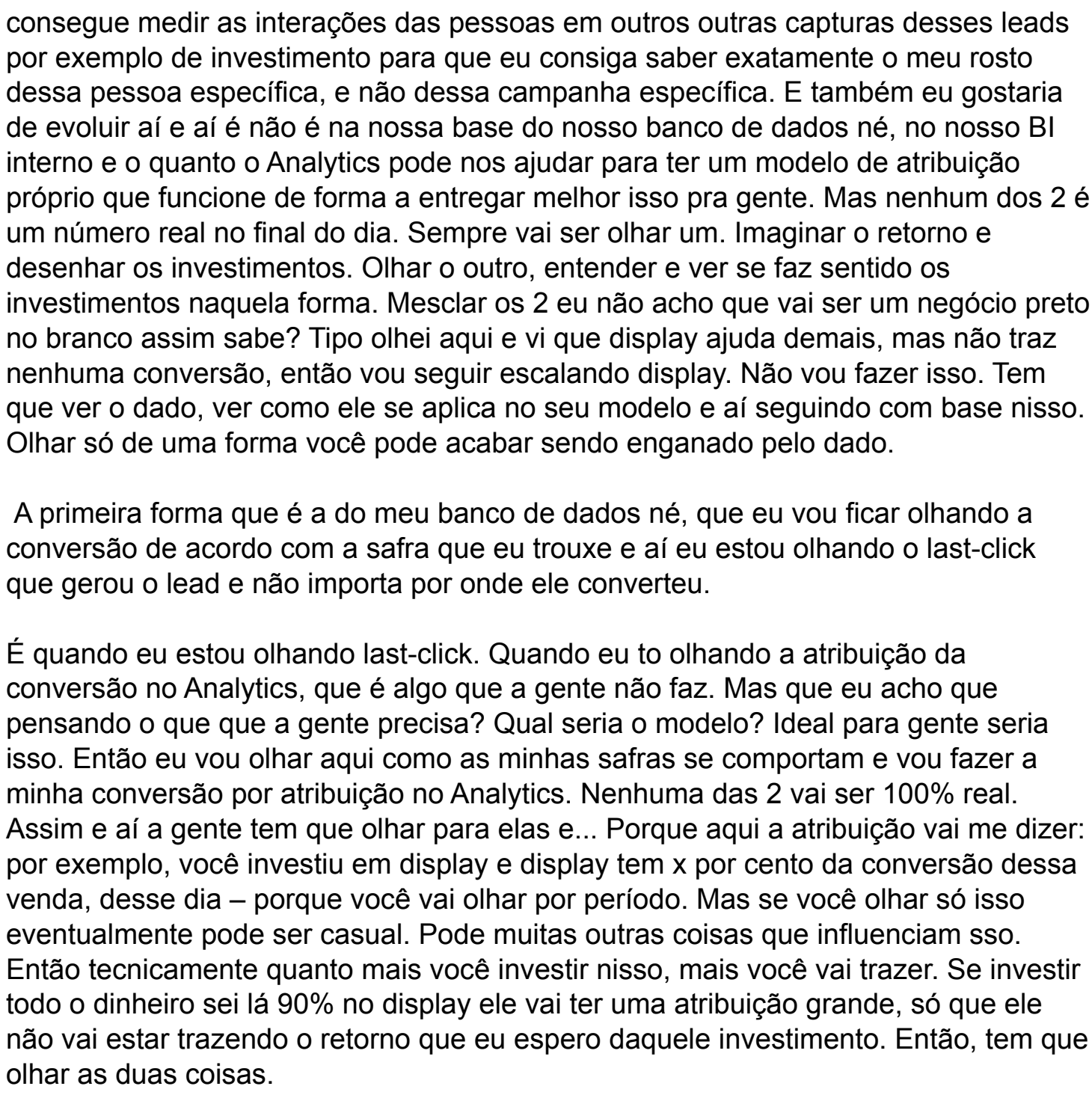 \\
\hline 8 & $\begin{array}{l}\text { Cara eu acho impossível isso acontecer. Mas eu vou responder tá? Mas eu acho que } \\
\text { é impossível porque se você me pedisse para desenhar um modelo de atribuição } \\
\text { para minha empresa eu não saberia. Você vai colocar uma série de coisas que talvez } \\
\text { não sejam reais. É uma tentativa e erro que vai e eventualmente atribuição é } 100 \% \\
\text { discricionário assim. Eu escolhi esse e aí seja o que Deus quiser. Você não vai } \\
\text { encontrar ninguém falar tipo que esse é o melhor modelo de atribuição do mundo e } \\
\text { que ele funciona } 100 \% \text {. Você vai escolher aqueles que menos te dá problema. Então } \\
\text { isso é impossível mas neu gostaria que fosse possível. É basicamente você ter uma } \\
\text { marionete nas mãos, você vai saber exatamente como o seu retorno vem. E aí você } \\
\text { vai poder direcionar os seus investimentos e o seu mix de forma perfeita. Se ele me } \\
\text { desse tudo que eu preciso, perfeito, personalizado para a jornada de consumo da } \\
\text { empresa, automático. Seria incrível poder escolher exatamente os investimentos de } \\
\text { acordo com o retorno, escalar ate onde e possível escalar. } \\
\text { É um negócio que a gente tem medo. Qualquer gestor financeiro de uma área de } \\
\text { marketing. Essa conta de quanto investir em relação ao retorno é muito difícil de } \\
\text { fazer. Você acaba um modelo de atribuição de forma sensacional. } \\
\text { E ainda que eu conseguisse entender a jornada de navegação das pessoas na }\end{array}$ \\
\hline
\end{tabular}




\begin{tabular}{|c|c|}
\hline & $\begin{array}{l}\text { internet como um todo, isso pode influenciar. Eu nunca vou conseguir entender no } \\
\text { mundo real. } \\
\text { Tem muitas outras coisas que também vão influenciar os seus investimentos sabe? } \\
\text { Porque estou investindo em Google e Facebook Ads. Mas eventualmente vão ter } \\
\text { coisas que a pessoa viu que vai leva-la a clicar no teu anúncio. É eventualmente vai } \\
\text { ter coisas que a pessoa viu que vai. Levá-la clicar no teu anúncio. Para dar um } \\
\text { exemplo exógeno muito claro: } \\
\text { Você não tem como influenciar para dar um exemplo exógeno muito claro a gente } \\
\text { trabalha no mercado financeiro né? Se a bolsa está indo bem, o nosso investimento, } \\
\text { o nosso ROAS vai ser melhor. Eu posso investir a mesma coisa. Se a bolsa está bem } \\
\text { o ROAS é melhor. É dado. Tudo igual. E aí como eu atribuo isso? } \\
\text { Imagina que eu ia ver o meu retorno aumentando. Mantive o mesmo investimento. } \\
\text { Mas seu começasse a ver o meu ROAS aumentar jamais eu ia manter o mesmo } \\
\text { budget. Então, imagina que eu não sei que a bolsa está bem, eu ia continuar } \\
\text { investindo ou imagina que nesse momento estou testando um canal novo. Você } \\
\text { nunca vai conseguir excluir fatores exógenos do seu investimento em marketing. } \\
\text { Mesmo que não tem nada a ver com o seu investimento diretamente. }\end{array}$ \\
\hline 9 & $\begin{array}{l}\text { A gente no começo usava modelo de atribuição quando a empresa tinha } 10,20 \\
\text { pessoas. Isso ajudava a gente a direcionar o marketing. O padrão. Um modelo de } \\
\text { atribuição do Google. A gente colocava peso maior para o primeiro e para o último } \\
\text { contato e usava isso pra direcionar o marketing com isso. E aí em algum momento o } \\
\text { Alexandre, o CEO, ele falou "cara, mas assim a gente não consegue medir a } \\
\text { melhoria dos canais nisso entendeu, tipo é foi exatamente exemplo que eu dei do } \\
\text { Google Ads, por exemplo. Eu posso investir muito, ele vai ser importante ali mas ele } \\
\text { não vai garantir que eu estou trazendo o retorno desejado. Então a gente pensou } \\
\text { "cara como é que a gente pode desenhar um modelo que nos entregue minimamente } \\
\text { a escolha de budget?" } \\
\text { A gente falou "cara o last-click do Analytics não vai funcionar desse jeito, porque a } \\
\text { gente tem alguns problemas de mensuração e tal que são padrão no Analytics" Tem } \\
\text { que ir pro banco de dados. Nisso que a gente começou a tirar tudo e colocar no } \\
\text { banco de dados e tentar medir por lá a compra last click. E aí, cara, basicamente, foi } \\
\text { o que a gente fez. A gente escolheu ter um modelo last click que fosse fora do } \\
\text { Analytics. } \\
\text { Um obstáculo então para te responder a gente não conseguia ter confiança que } \\
\text { aquele modelo ia entregar exatamente a resposta que a gente precisava. Só que a } \\
\text { gente foi pra um modelo muito mais difícil de manter entendeu? Então eu acho que } \\
\text { a gente hoje gera até mais inteligência que poderia se a gente tivesse só no } \\
\text { Analytics só que é impossível de manter. } \\
\text { E aí nesse modelo eu acho que a gente tem um modelo de atribuição, que é um } \\
\text { modelo de atribuição last clique, por canal e a gente avalia métricas que a gente não } \\
\text { avalia no Analytics. Beleza, então a gente tem e a gente está aprimorando, só que é } \\
\text { difícil manter, um investimento enorme interno e é muito pouco funcional para } \\
\text { qualquer outra coisa que a gente precise. } \\
\text { Se for entre levar isso pro Analytics ou qualquer levar algum tipo dessa análise pro } \\
\text { Analytics - aquela outra parte que eu falei e ter algum tipo de atribuição lá - isso é }\end{array}$ \\
\hline
\end{tabular}


zero prioridade hoje. A gente tem um modelo que está minimante desenhado e que funciona bem para o nosso negócio no estágio atual. O próprio passo não é prioridade no momento. 